IZA DP No. 1872

Two Faces of the ICT Revolution:

Desegregation and Minority-Majority

Earnings Inequality

Martin Kahanec

December 2005 


\title{
Two Faces of the ICT Revolution: Desegregation and Minority-Majority Earnings Inequality
}

\author{
Martin Kahanec
}

IZA Bonn

\section{Discussion Paper No. 1872 \\ December 2005}

\author{
IZA \\ P.O. Box 7240 \\ 53072 Bonn \\ Germany \\ Phone: +49-228-3894-0 \\ Fax: +49-228-3894-180 \\ Email: iza@iza.org
}

Any opinions expressed here are those of the author(s) and not those of the institute. Research disseminated by IZA may include views on policy, but the institute itself takes no institutional policy positions.

The Institute for the Study of Labor (IZA) in Bonn is a local and virtual international research center and a place of communication between science, politics and business. IZA is an independent nonprofit company supported by Deutsche Post World Net. The center is associated with the University of Bonn and offers a stimulating research environment through its research networks, research support, and visitors and doctoral programs. IZA engages in (i) original and internationally competitive research in all fields of labor economics, (ii) development of policy concepts, and (iii) dissemination of research results and concepts to the interested public.

IZA Discussion Papers often represent preliminary work and are circulated to encourage discussion. Citation of such a paper should account for its provisional character. A revised version may be available directly from the author. 


\section{ABSTRACT \\ Two Faces of the ICT Revolution: Desegregation and Minority-Majority Earnings Inequality}

Social interaction is the primary vehicle through which advancement of information and communication technologies (ICT) affects socio-economic outcomes. In the context of minority-majority relations, social distances and segregation determine the benefits individuals gain from social interaction and from improvement of its efficiency. In the general equilibrium framework, this paper argues that ICT advancement disproportionately increases the efficiency of social interaction in ethnically integrated social networks and that of majority individuals, thereby causing desegregation and increasing interethnic earnings inequality at the same time. The argument thus explains the concurrence of two seemingly contradicting developments in the lives of Black and White Americans since the late 1970s - rising interethnic earnings inequality and desegregation of Blacks. Furthermore, I establish that there is a threshold level of ICT below which all minority individuals prefer segregated neighborhoods and above which some minority individuals choose to integrate, thereby reaping the efficiency benefits of social interaction with the larger society. I interpret the reversal of the segregation trend that occurred in the late 1970 s as a consequence of advancement of ICT beyond this threshold level. Finally, I suggest an explanation of why typically no desegregation occurred in extraordinarily segregated areas and in the case of recent immigrants.

JEL Classification: J15, J71, O15, O33

Keywords: segregation, earnings inequality, minority, social interaction, ICT revolution, migration

Corresponding author:

Martin Kahanec

IZA

P.O. Box 7240

53072 Bonn

Germany

Email: kahanec@iza.org

\footnotetext{
" I am grateful to Sjak Smulders, Javier Ortega, Fabien Moizeau, Anne Gielen, Piotr Stryszowski, and the participants of the SASE 2005 conference in Budapest and various seminars and workshops at CentER, Tilburg University, and MPSE, University of Toulouse 1, for helpful advice on the earlier drafts of this paper. All remaining errors are mine. Financial support from Volkswagen Foundation for the IZA project on "The Economics and Persistence of Migrant Ethnicity" is gratefully acknowledged.
} 


\section{Introduction}

Since the late 1970s Americans have been witnessing three major developments in their social and economic life. First, information and communication technologies (ICT), which is the umbrella term that denotes any information processing and communication technology, device, or application, have changed the life of the average American tremendously. What started as face-to-face communication in primeval ages and went through less and more advanced stages such as smoke and drum signals, the alphabet, print and reproduction technologies, and telephone, turned into a sweeping development during the last quarter of the $20^{\text {th }}$ century. The new information and communication technologies that emerged and went mainstream during this so-called ICT revolution include advanced fax and telephony technologies, satellite communication, and computer and network hardware and software, such as word and table processors, e-mail, search engines, and Internet databases and encyclopedias. These technologies immensely improved technological efficiency of interpersonal communication and data processing and storing. In short, the ICT revolution enabled ordinary people to exchange information over large distances at relatively low and still decreasing costs.

Another major development in the context of cohabitation of minority and majority ${ }^{1}$ people in the U.S. was the reversal of segregation trends in the late seventies and desegregation of the Black minority thereafter. ${ }^{2}$ In particular, while the first three quarters of the $20^{\text {th }}$ century can generally be characterized by increasing degree of segregation, the last quarter witnessed a steady decline of segregation of the Black minority. Massey and Denton (1987) observe some signs of desegregation of Blacks during the 1970s. Farley

\footnotetext{
${ }^{1}$ Throughout the paper minority is understood to be a particular racial, ethnic, language, or religious group of individuals who share socio-cultural characteristics such as culture, religion, language, history, beliefs, customs, values, and morals that make them distinct from the rest of the population - the majority. While there may be regions where the minority outnumbers the majority, that minorities constitute smaller proportion of population than majorities is a part of most definitions of the minority. This study does not deal with social groups formed on the basis of occupation, wealth, or other ordinal characteristics.

${ }^{2}$ Segregation is understood to be separation of people according to their social, ethnic, racial, religious, or other characteristics in social interaction. Some of the most visible forms of segregation are geographical segregation, as exhibited by e.g. racial segregation of neighborhoods, and social segregation, as found in segregated schools or workplaces. The segregation literature is immense, including DuBois (1899), Myrdal (1944), Taeuber and Taeuber (1965), Massey and Denton (1987, 1993), and Farley and Frey (1994).
} 
and Frey (1994) suggest that segregation between Blacks and Whites started to decline during the 1970s and find pervasive declines of segregation of Blacks during the 1980s. Cutler et al. (1999) provide evidence that segregation of native-born Blacks in the US was increasing since the last decade of the $19^{\text {th }}$ century until the Second World War, it consolidated and expanded between 1940 and 1970, and since the 1970s segregation has been steadily declining. ${ }^{3}$ These segregation patterns are depicted by Figure 1. One can observe that index of dissimilarity and index of isolation ${ }^{4}$ between native-born Blacks and Whites exhibit the same pattern: both are increasing until the 1960-70s and exhibit a steady decline thereafter.

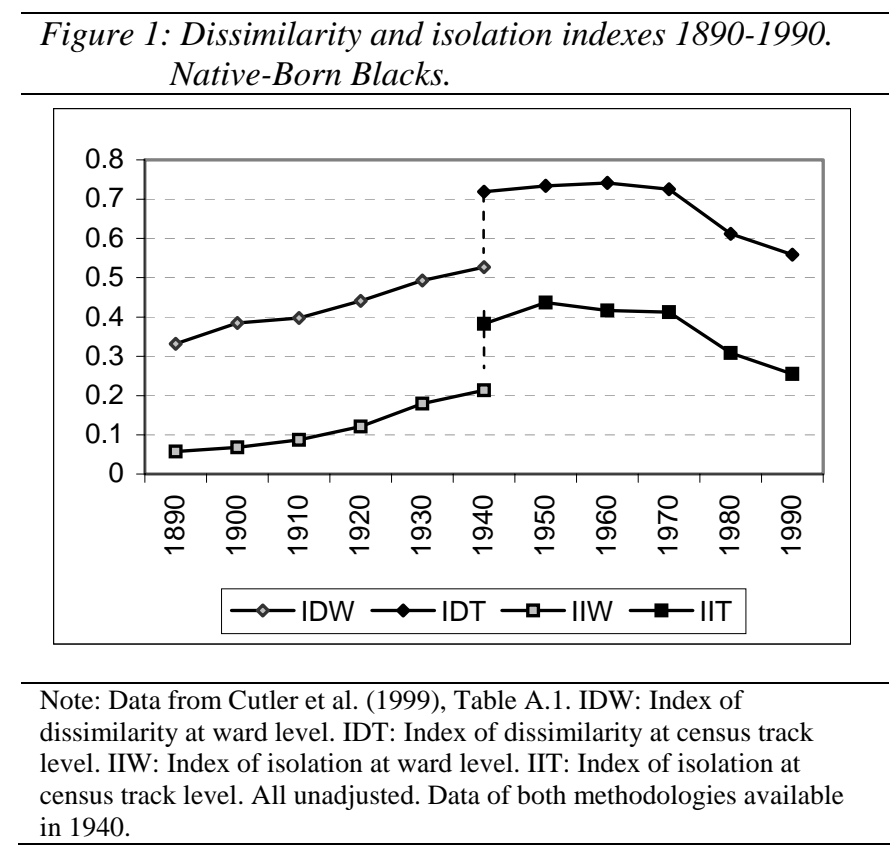

Finally, although the period after the 1970s has been characterized by desegregation, which is generally believed to reduce ethnic (earnings) differentials, the socioeconomic gap between ethnic and racial groups has been widening. In particular, as demonstrated by Altonji and Blank (1998), following a period of catching up during the 1960s, earnings gaps among racial and ethnic groups have been on the rise since the mid-1970s.

\footnotetext{
${ }^{3}$ The evidence is less clear for the Hispanic and Asian minorities, largely due to sizeable recent immigration. See Massey and Denton (1987) and Frey and Farley (1996).

${ }^{4}$ Indexes of dissimilarity and isolation are perhaps the two most widely used measures of segregation. The former tells us what share of the minority (or majority) population would need to relocate for the races to be evenly distributed. The latter measures the exposure of minority to majority. See Taeuber and Taeuber (1965), Duncan and Duncan (1955), and Bell (1954).
} 
While Black men reduced and Black women almost closed the earnings gap during the 1960s when certain antidiscriminatory laws were adopted, ${ }^{5}$ the relative earnings of Black men stagnated or somewhat deteriorated and the relative wages of Black women clearly declined since the 1970s, as compared to their White counterparts. Such deterioration was even more pronounced for Hispanic men and women. ${ }^{6}$ Figures 2 and 3 depict trends in racial earnings inequality for Black and Hispanic workers vis-à-vis White workers by gender from 1979 till 2002. The general pattern one can observe is that the relative earnings of minority workers declined during this period.

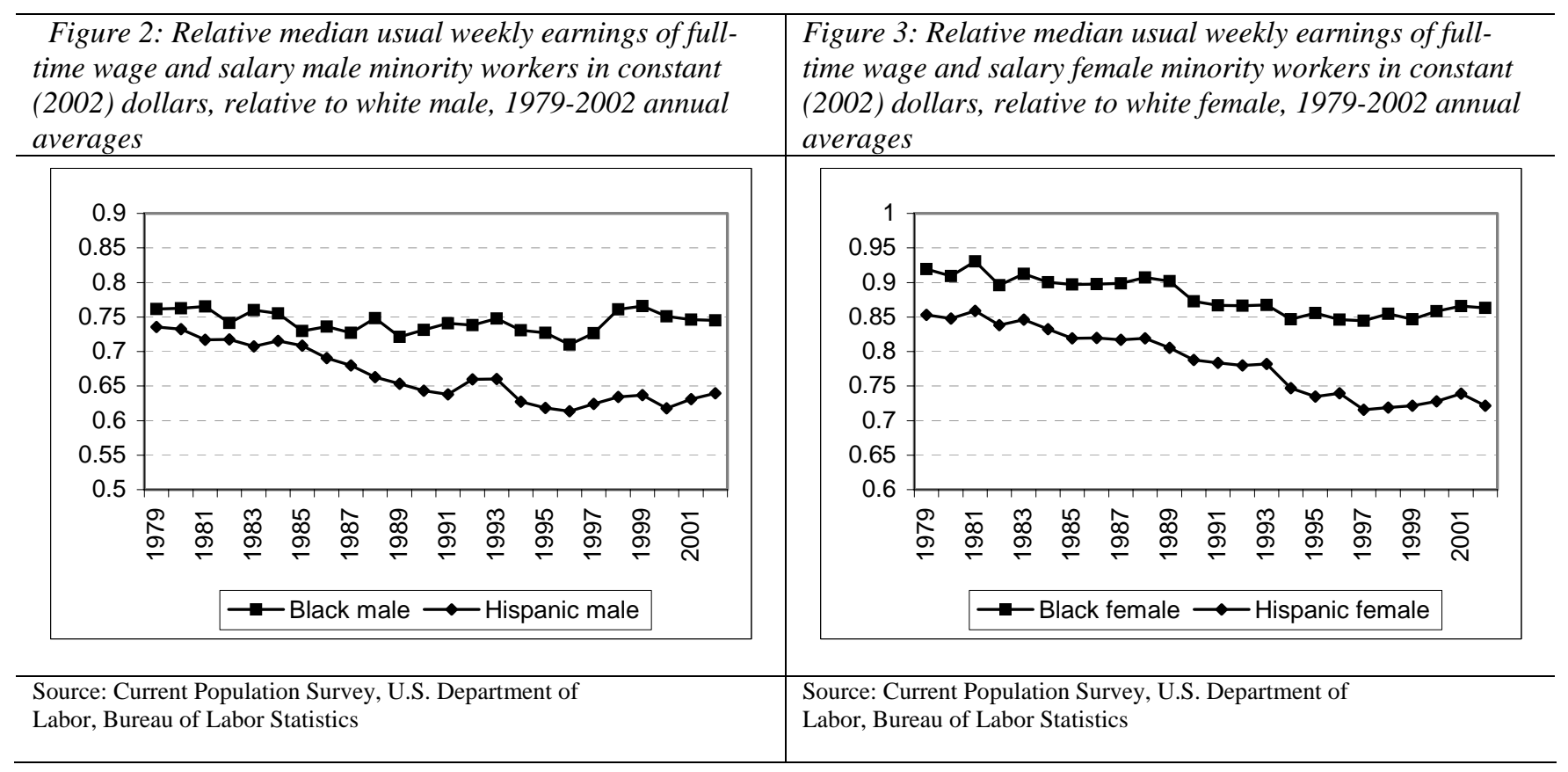

Several explanations of desegregation and increasing earnings inequality during the recent decades in the US have been suggested in the literature. Concerning desegregation, Schuman et al. (1985), Schuman and Bobo (1988), and Farley and Frey (1994) argue that the opposition of whites against minority neighbors has been on decline, resulting in a larger number of non-white settlers in "white" neighborhoods and desegregation, in turn. ${ }^{7}$ Cutler et al. (1999) argue that it is the elimination of formal barriers to integration that

\footnotetext{
${ }^{5}$ See e.g. Heckman and Payner (1989), Donohue and Heckman (1991), and Neumark and Stock (2001).

${ }^{6}$ Altonji and Blank (1998), p. 3149.

${ }^{7}$ Several scholars, including Farley and Frey (1994), claim that actual levels of resistance against racially mixed living remain high, however.
} 
brought about reversal of segregation trends in the 1970s and caused desegregation thereafter.

In regard of the increasing earnings inequality during the last quarter of the $20^{\text {th }}$ century, Juhn et al. (1991) argue that much of the increase can be explained by the general trend of increasing earnings inequality during this period and the placement of Black workers in the lower end of the earnings distribution. They also establish that part of the increase may be due to racial differences in unobservable school quality. Juhn et al. (1991) and Card and Lemieux (1996) find that changes in returns to skills had a strong negative effect on the Black-White earnings ratio in recent decades. Bound and Freeman (1992) argue that a large fraction of Black-White earnings gap increase can be explained by industrial shifts such as decline in durable manufacturing and regional shifts including changes in metropolitan location. In addition, they also argue that the increase in the supply of young Black college graduates and the resulting deterioration of their wages contributed to the overall increase in Black-White earnings inequality.

The purpose of this paper is to argue that the concurrence of the three abovementioned phenomena is not coincidental and that there are fundamental causal relationships among them. In particular, I offer a novel explanation of the concurrence of desegregation and increasing earnings inequality, arguing that ICT advancement has two faces in the context of minority-majority social and economic interaction: it contributes to desegregation of minority individuals and drives a wedge between minority and majority earnings. Furthermore, I elucidate why no desegregation occurred in extraordinarily segregated areas and in the case of recent immigrants and offer an explanation why the reversal of the segregation trend occurred in the late 1970s. ${ }^{8}$ The arguments are based on the role of social interaction in human capital acquisition and the effects of ICT improvement on social interaction, which I discuss in the next section.

\footnotetext{
${ }^{8}$ See Cutler et al. (1999) and Cutler et al. (2005).
} 


\section{The Social and Economic Environment}

Social interaction is the prime vehicle through which advancements of communication and information technologies, such as those pertaining to the ICT revolution, affect social organization and economic outcomes. A number of scholars, including Gaspar and Glaeser (1996), Lin (1999), Wellman et al. (1996, 2001), and Feldman (2002) argue that advancements of ICT significantly reduce the costs of exchanging and processing information and make it possible to exchange more complex information, thereby facilitating social interaction. Gaspar and Glaeser (1996) offer several pieces of evidence in support of the positive role of the telephone on social interaction. The positive effect of Internet use on social interaction is supported by empirical studies such as Uslaner (1999), Cole (2000), Hampton and Wellman (2000), and Robinson et al. (2000), who report that Internet users have higher levels of trust and larger social networks. ${ }^{9}$ Based on this literature, I adopt the premise that ICT advancement significantly improves the efficiency of social networks and thereby increases the scope and intensity of social interaction. ${ }^{10}$

While technological advancements due to the ICT revolution have facilitated social interaction, there are features of social organization that have constrained it. Segregation is a prime phenomenon of this kind in the context of minority-majority social interaction. It impedes and possibly precludes social interaction between individuals who are segregated and the rest of the society. Another phenomenon that hinders minoritymajority social interaction is social distance that encompasses socio-cultural differences between minority and majority individuals, as discussed by e.g. Poole (1927) and Lazear (1999). Difficulties to understand the language, habits, culture, and other characteristics

\footnotetext{
${ }^{9}$ See also Kraut et al. (1998) and Nie and Erbring (2000), who report that the use of Internet may have detrimental effects on other forms of social interaction, especially for inexperienced and incompetent Internet users.

${ }^{10}$ Social network is understood to be a social structure between individual actors that facilitates social interaction between its members.
} 
of the other social group reduce the efficiency of social interaction between socially distant minorities and majorities. ${ }^{11}$

That social interaction in social networks is an important vehicle of human capital acquisition was pointed out by e.g. Allen (1982), Lucas (1988), Ellison and Fudenberg (1993, 1995), and Bala and Goyal (1998). ${ }^{12}$ Conley and Udry (2002), Foster and Rosenzweig (1995), and Munshi (2002) argue that social interaction facilitates learning, documenting that farmers learn about the best practices in social interaction with their peers and neighbors. A number of scholars, such as Glaeser et al. (2002), Foster and Rosenzweig (1995), and Lazear (1999), maintain that social interaction in social networks typically involves positive externalities such that the aggregate resources of a network exceed the naïve sum of individual contributions. In line with this literature, I adopt the premise that social interaction is an important input in human capital acquisition that involves external network effects ${ }^{13}$ that positively depend on the size of social networks in which skills are acquired.

There are several arguments that the character of environment in which human capital is acquired affects its type and, in particular, that segregated and integrated environments differ with respect to human capital that they support. First, ethnic exclusiveness of segregated social networks gives rise to skill specialization that reflect the purpose of segregated social networks, as compared to integrated social networks that prevail in integrated social networks. If, for example, an ethnic group develops segregated social networks to support their specialization in certain sectors of economy, such as ethnic restaurants or certain crafts, ${ }^{14}$ skills available in these social networks differ from those available in integrated social networks. Second, social interaction in segregated social

\footnotetext{
${ }^{11}$ The main distinction between segregation and social distance is that while segregation is an endogenous feature of societal organization, social distance is the defining socio-cultural difference between minority and majority people.

${ }^{12}$ The literature on social embeddedness of human capital acquisition includes Rees and Schultz (1972), Loury (1977), Bourdieu (1986), and Coleman $(1988,1990)$.

${ }^{13}$ Network effects arise whenever benefits from a good or service, here the service of social network in skill acquisition process, increase in the number of individuals already owning that good or using that service. One consequence of a network effect is that the use of a network service by one individual indirectly benefits others who use it. This side effect in a transaction is known as network externality. ${ }^{14}$ Well documented is specialization of Gypsy communities in various crafts. See Fraser (1992).
} 
networks is more prone to bear a specific cultural imprint than that in integrated social networks. ${ }^{15}$ Finally, to the extent that segregation prevents flow of ideas and innovations and their adoption, segregated social environment perpetuates and supports different skills than integrated one. Ethnic environment, in particular, has spillover effects on the human capital accumulation process and affects the type and quality of skills acquired. ${ }^{16}$ Given these arguments, the type of human capital acquired in segregated social networks generally differs from that acquired in integrated social networks. Given this distinction, hereafter "segregated" and "integrated" specify notions, such as labor and wages, pertaining to the respective type of social network and its members.

While segregation may result from external forces such as discrimination, in this paper I study segregation as a function of the choice of minority people between segregated and integrated social networks. In particular, I focus on the role of an economic factor earnings under segregation and integration - on individual decision to segregate (integrate). Given the premises developed above it follows that individual choice between segregated and integrated social networks involves two major aspects. First, it entails the wage tradeoff, since the choice between segregation and integration involves choosing between the two different types of human capital to acquire and thus between different wages per efficiency unit of labor supplied. Second, it involves the efficiency tradeoff, as the composition of members of a segregated social network is different from that of an integrated social network and thus, due to social distances and network effects, for any given agent the efficiencies of skill acquisition differ between segregated and integrated social networks.

Corresponding to the wage and efficiency tradeoffs, two mechanisms govern the degree of segregation in the economy on the aggregate level. First, as the share of minority people who choose segregation increases, so does the relative supply of segregated labor. This increase has a negative effect on the relative wage for segregated labor through the textbook substitution mechanism. Second, through the efficiency mechanism, a larger

\footnotetext{
${ }^{15}$ See Hofstede (1980), Sowell (1994), and Kraus and Hodge (1990).

${ }^{16}$ See Borjas (1994).
} 
number of people in segregated social networks generate larger network effects in these networks. In particular, it improves their relative efficiency vis-à-vis integrated social networks, which suffer a decrease in their size and thus network effects. Under certain conditions, the substitution and efficiency effects give rise to an equilibrium degree of segregation in which for no integrated individual switching to segregation and no segregated individual switching to integration pays off, as segregated and integrated earnings are equal.

The main proposition of this paper is that advancement of information and communication technologies, such as that pertaining to the ICT revolution, stimulates desegregation of minority individuals and increases minority-majority earnings inequality. The reason why ICT advancement causes desegregation is that it intensifies social interaction and thus increases the weight of the efficiency aspect, which favors desegregation, in the abovementioned tradeoff. On the other hand, ICT improvement favors the majority, as their efficiency gains from the intensified social interaction are larger than those of minority individuals, whose small relative size and social distance to the relatively large number of majority individuals significantly constrain their benefits from the ICT-driven efficiency enhancement.

The argument proceeds as follows. In the next section I develop a general equilibrium model and depict the equilibrium degree of segregation therein. In Section 3 I study the effects of the ICT revolution on equilibrium segregation and interethnic earnings inequality. In Section 4 I offer an explanation why the reversal of segregation trends coincided with the onset of the ICT revolution. Thereafter I summarize and discuss the model and conclude. 


\section{The Model}

\subsection{Demand}

To investigate the effects of the ICT revolution on minority-majority segregation and earnings inequality I study an economy populated by the continua of minority and majority individuals with measures $I$ and $J$ and elements $i$ and $j$, respectively. The size of the economy is conveniently normalized to unity such that $I+J=1$. All individuals are identical with respect to their preferences and endowments, group membership excepting. Individual preferences are represented by a standard utility function $u(\cdot)$ defined on the domain of individual consumption of the consumption good, $C_{k}$, where $k \in\{i, j\}$. Let $I_{\text {seg }}$ denote the mass of minority individuals that choose segregation and (alone) constitute segregated social networks and $I_{\text {int }}$ the mass of those that choose integration and interact with majority individuals in integrated social networks. Thus, $I_{\text {seg }}+I_{\text {int }}=I$.

Let the consumption good be produced by combining labor inputs of segregated and integrated minority agents, $H_{i, \text { seg }}$ and $H_{i, \text { int }}$, respectively, and majority agents, $H_{j}$, in a perfectly competitive industry according to the constant elasticity of substitution (CES) aggregate production function

$$
C=\left(\left(\int_{0}^{I_{\text {seg }}} H_{i, \text { seg }} d i\right)^{\rho-1) / \rho}+\left(\int_{0}^{I_{\text {int }}} H_{i, \text { int }} d i+\int_{0}^{J} H_{j} d j\right)^{(\rho-1) / \rho}\right)^{\rho /(\rho-1)}
$$

with the elasticity parameter $\rho>1$. As argued above, labor supplied by segregated minority individuals is an imperfect substitute for labor supplied by majority and integrated minority individuals. For expositional convenience, labor of integrated minority individuals is assumed to be perfectly substitutable with that of majority individuals.

Applying the representative agent hypothesis group-wise and, given the infinitesimal measure of an individual, taking all prices as given on the individual level, production function (1) implies that individuals face the following demands for their labor:

$$
H_{i, s e g}=P_{C}^{\rho} W_{\text {seg }}^{-\rho} C / I_{\text {seg }}
$$




$$
J H_{j}+I_{i n t} H_{i, \text { int }}=P_{C}^{\rho} W_{i n t}^{-\rho} C,
$$

where $P_{C}$ is the price of composite consumption good $C$ and $W_{\text {seg }}$ and $W_{\text {int }}$ are the wages per efficiency unit of labor of segregated and integrated individuals, respectively. ${ }^{17}$ As a result of the homogeneity of degree one of the CES production function, the sector does not generate any profits in the equilibrium and one can derive that $P_{C}=\left(W_{\text {seg }}^{1-\rho}+W_{\text {int }}^{1-\rho}\right)^{1 /(1-\rho)}$.

\subsection{Supply}

On the supply side, taking the actions of other agents and wages as given, individuals aim to maximize their earnings by maximizing the amount of efficient labor they supply on the labor market. In particular, each individual is endowed with one unit of labor time that is, adopting a simplifying assumption, inelastically supplied on the labor market. However, individuals increase the efficiency of their labor by acquiring human capital in social interaction. The labor that they supply in the labor market measured in efficiency units, efficient labor, is then conceptualized to be the product of labor time and human capital.

Minority individuals choose between segregated and integrated social networks to acquire human capital, while all majority individuals are, by assumption, members of integrated social networks. ${ }^{18}$ As discussed above, individuals benefit from social interaction with other individuals and these benefits increase in the number of people with whom the particular individual interacts. Furthermore, benefits from social interaction are constrained by segregation and social distance. By assumption, segregated minority individuals do not interact with integrated individuals and vice versa. ${ }^{19}$ To

\footnotetext{
${ }^{17}$ Note here that $W_{\text {seg }}$ is the wage of integrated minority as well as majority, whose efficient labors are by assumption perfectly substitutable and thus earn the same unit wage.

${ }^{18}$ In effect, two sets of social networks exist in the economy: segregated ones that involve exclusively minority people who choose to segregate and integrated ones where all majority people and those minority people that chose to integrate interact.

19 This extreme assumption of zero social interaction between integrated and segregated social groups serves the purpose of exposition and has no bearing on the main results of this paper.
} 
capture these assumptions in social interaction, it is assumed that human capital is acquired and thus efficient labor ${ }^{20}$ is supplied as follows:

$$
\begin{aligned}
& H_{i, \text { seg }}=1+I_{\text {seg }}^{\gamma} \\
& H_{i, \text { int }}=1+I_{i n t}^{\gamma}+\frac{1}{1+\delta} J^{\gamma} \\
& H_{j}=1+\frac{1}{1+\delta} I_{i n t}^{\gamma}+J^{\gamma},
\end{aligned}
$$

where the parameter $\delta \geq 0$ captures social distance between minority and majority individuals. In particular, benefits from social interaction with socially distant individuals are discounted by the social distance factor $1 /(1+\delta)$. Because $\delta \geq 0$, this factor ranges between zero and one. That marginal benefits from social interaction are nonincreasing in the number of interacting people is captured by the parameter $\gamma$, where $0<\gamma \leq 1$. Reasonably, if no social interaction takes place, individual efficient labor is equal to the endowed unit of labor time.

Having delineated fundamental relationships of the economy, I now turn to solving for earnings of segregated and integrated minority individuals and majority individuals, which determine incentives for switching between segregation and integration. Normalizing $P_{C}=1$ and using equations (5.2a-b) and (5.3a-c), we solve for wages for segregated and integrated efficient labor to obtain:

$$
\begin{aligned}
& W_{\text {seg }}=\left(\frac{C}{H_{i, \text { seg }} I_{\text {seg }}}\right)^{\frac{1}{\rho}} \\
& W_{\text {int }}=\left(\frac{C}{H_{j} J+H_{i, \text { int }} I_{\text {int }}}\right)^{\frac{1}{\rho}},
\end{aligned}
$$

where $C$ is computed by plugging (5.3a-c) into (1) to obtain:

$$
C=\left(\left(\left(1+I_{\text {seg }}^{\gamma}\right) I_{\text {seg }}\right)^{(\rho-1) / \rho}+\left(\left(1+\frac{1}{1+\delta} I_{\text {int }}^{\gamma}+J^{\gamma}\right) J+\left(1+I_{\text {int }}^{\gamma}+\frac{1}{1+\delta} J^{\gamma}\right) I_{\text {int }}\right)^{(\rho-1) / \rho}\right)^{\rho /(\rho-1)} .
$$

\footnotetext{
${ }^{20}$ Because the endowed unit of time is inelastically supplied and efficient labor is the product of labor time and human capital, efficient labor is analytically equal to human capital.
} 
It follows that segregated and integrated minority and majority earnings are, respectively:

$$
\begin{aligned}
& \Omega_{i, \text { seg }} \equiv W_{\text {seg }} H_{i, \text { seg }}=\left(\frac{C}{\left(1+I_{\text {seg }}^{\gamma}\right) I_{\text {seg }}}\right)^{\frac{1}{\rho}}\left(1+I_{\text {seg }}^{\gamma}\right) \\
& \Omega_{i, \text { int }} \equiv W_{\text {int }} H_{i, \text { int }}=\left(\frac{C}{\left(1+I_{\text {int }}^{\gamma}+\frac{1}{1+\delta} J^{\gamma}\right) I_{\text {int }}+\left(1+\frac{1}{1+\delta} I_{\text {int }}^{\gamma}+J^{\gamma}\right) J}\right)^{\frac{1}{\rho}}\left(1+I_{\text {int }}^{\gamma}+\frac{1}{1+\delta} J^{\gamma}\right) \\
& \Omega_{j} \equiv W_{\text {int }} H_{j}=\left(\frac{C}{\left(1+I_{\text {int }}^{\gamma}+\frac{1}{1+\delta} J^{\gamma}\right) I_{\text {int }}+\left(1+\frac{1}{1+\delta} I_{\text {int }}^{\gamma}+J^{\gamma}\right)}\right)^{\frac{1}{\rho}}\left(1+\frac{1}{1+\delta} I_{\text {int }}^{\gamma}+J^{\gamma}\right),
\end{aligned}
$$

where $C$ is defined in equation (5).

\subsection{Equilibrium Segregation}

Having formulated the earnings functions of segregated and integrated minority individuals, I am now equipped to study distribution of minority individuals across the two types of social networks and, in particular, the equilibrium degree of segregation in the economy. Recalling that each individual takes the decisions of other agents as given, minority individuals compare earnings under segregation $\Omega_{i, \text { seg }}$ and under integration $\Omega_{i, i n t}$ when deciding what kind of social network to join. Because the costs of switching between social networks are not central to the argument, I assume that switching is frictionless. ${ }^{21}$ Under these conditions, segregation equilibrium is characterized by the following equilibrium conditions:

$$
\begin{aligned}
& \Omega_{i, s e g} \geq \Omega_{i, \text { int }} \text { if } I_{\text {seg }}=I \\
& \Omega_{i, \text { seg }} \leq \Omega_{i, \text { int }} \text { if } I_{\text {seg }}=0 \\
& \Omega_{i, \text { seg }}=\Omega_{i, \text { int }} \text { if } 0<I_{\text {seg }}<I .
\end{aligned}
$$

\footnotetext{
${ }^{21}$ Switching costs can easily be incorporated into the model; this would yield no further insight with respect to the main argument, however.
} 
The first two conditions apply to corner equilibria of full segregation (7a) and full integration (7b) and say that if all minority individuals choose to segregate (integrate), earnings under segregation (integration) must be at least as high as those under integration (segregation) for each and every minority individual. The last condition applies to the case in which some minority segregate and some integrate. Clearly, in such case the economy is in equilibrium if and only if switching does not pay off, that is, if earnings of segregated minority individuals are equal to those of integrated individuals. This is exactly what condition (7c) says. Defining $\omega\left(I_{\text {seg }}\right) \equiv \Omega_{i, \text { seg }} / \Omega_{i, \text { int }}$ and noting that $\Omega_{\text {int }}>0$, condition (7c) is equivalent to $\omega\left(I_{\text {seg }}\right)=1$. Upon substitution and straightforward manipulation, $\omega\left(I_{\text {seg }}\right)=1$ is equivalent to the following arbitrage condition:

$$
\left(\frac{\left(1+I_{\text {int }}^{\gamma}+\frac{1}{1+\delta} J^{\gamma}\right) I_{\text {int }}+\left(1+\frac{1}{1+\delta} I_{\text {int }}^{\gamma}+J^{\gamma}\right) J}{\left(1+I_{\text {seg }}^{\gamma}\right) I_{\text {seg }}}\right)^{\frac{1}{\rho}} \frac{1+I_{\text {seg }}^{\gamma}}{1+I_{\text {int }}^{\gamma}+\frac{1}{1+\delta} J^{\gamma}}=1 .
$$

Because $I_{\text {seg }}$ is the only endogenous variable in the arbitrage condition (AC), it fully determines the equilibrium value of $I_{\text {seg }}, I_{\text {seg }}^{e}$, and thus the equilibrium share of minority people who segregate in the interior equilibrium.

To depict what kind of interior segregation equilibria can occur in this model, I investigate the properties of $\omega\left(I_{\text {seg }}\right)$ as a function of $I_{\text {seg }}$. Denoting the ratio of human capitals of segregated and integrated minority individuals $h\left(I_{\text {seg }}\right) \equiv H_{i, \text { seg }} / H_{i, \text { nnt }}$ and the ratio of segregated and integrated wages $w\left(I_{\text {seg }}\right) \equiv W_{\text {seg }} / W_{\text {int }}$, the function $\omega\left(I_{\text {seg }}\right)=h\left(I_{\text {seg }}\right) w\left(I_{\text {seg }}\right)$ is governed by the properties of $w\left(I_{\text {seg }}\right)$ and $h\left(I_{\text {seg }}\right)$, which are driven by efficiency and substitution mechanisms, respectively.

In particular, through the efficiency mechanism, $h\left(I_{\text {seg }}\right)$ increases in the number of segregated minority, that is, $\partial h\left(I_{\text {seg }}\right) / \partial I_{\text {seg }}>0$. This follows straightforwardly from 


$$
h\left(I_{\text {seg }}\right)=\frac{1+I_{\text {seg }}^{\gamma}}{1+\left(I-I_{\text {seg }}\right)^{\gamma}+\frac{1}{1+\delta} J^{\gamma}}
$$

that one obtains by plugging (3a) and (3b) in the definition of $h\left(I_{\text {seg }}\right)$ above.

It has to be realized, however, that the efficiency mechanism does not necessarily favor integration. In particular, comparing the human capital acquisition technologies (3a) and (3b), let us state the integration efficiency condition (IEC) under which the efficiency of social interaction of minority individuals is higher in integrated social networks than in segregated ones, that is, $H_{i, s e g}<H_{i, \text { int }}$ :

$$
(1+\delta)\left(I_{\text {seg }}^{\gamma}-\left(I-I_{\text {seg }}\right)^{\gamma}\right)<J^{\gamma} \text {. }
$$

This condition holds whenever the number of integrated individuals is sufficiently larger than the number of segregated ones and social distance is not too large, such that for minority individuals the network benefits generated in integrated social networks are higher than those in segregated social networks and integration involves relatively little inefficiency caused by social distance. While this condition depends on the actual degree of segregation $I_{\text {seg }}$, it holds for any $I_{\text {seg }}$ whenever $\delta<(J / I)^{\gamma}-1$. Furthermore, condition (IEC) is more likely to hold if the degree of segregation is relatively small. More specifically, it can easily be seen that there always exists $I_{\text {seg }}$ that satisfies condition (IEC) and, in particular, any $I_{\text {seg }}<I / 2$ does so.

Concerning the substitution mechanism, $w\left(I_{\text {seg }}\right)$ decreases in the number of segregated minority people, that is, $\partial w\left(I_{\text {seg }}\right) / \partial I_{\text {seg }}<0$. This is so because segregating minority individuals increase the supply of segregated human capital and decrease the supply of integrated human capital through two mechanisms. First, the direct effect of increasing segregation on numbers of suppliers of segregated and integrated labor is obvious. Second, there is an indirect effect through which segregation increases per capita supply of human capital of segregated individuals at the expense of integrated individuals through the efficiency mechanism. Given the imperfect elasticity of substitution of 
segregated and integrated human capitals in production, these supply changes depress segregated wage relative to integrated wage. This readily follows from

$$
w\left(I_{\text {seg }}\right)=\left(\frac{\left(1+\left(I-I_{\text {seg }}\right)^{\gamma}+\frac{1}{1+\delta} J^{\gamma}\right)\left(I-I_{\text {seg }}\right)+\left(1+\frac{1}{1+\delta}\left(I-I_{\text {seg }}\right)^{\gamma}+J^{\gamma}\right) J}{\left(1+I_{\text {seg }}^{\gamma}\right) I_{\text {seg }}}\right)^{\frac{1}{\rho}}
$$

that is obtained by plugging (5.3a-c) and (5.4a-b) in the definition of $w\left(I_{\text {seg }}\right)$. In particular, note that the nominator is decreasing and denominator increasing in $I_{\text {seg }}$.

Therefore, the efficiency and substitution mechanisms work in the opposite directions. It turns out that the elasticity of substitution between segregated and integrated human capitals $\rho$ is the key parameter that governs $\omega\left(I_{\text {seg }}\right)$. In particular, while the efficiency mechanism is unaffected by $\rho$, as apparent form equation (8), the strength of the substitution mechanism is decreasing in this elasticity and is not present in the extreme case of perfect substitutability of segregated and integrated labor. This is evident from equation (9), where $\rho$ appears in the denominator of the exponent. It follows that $\rho$ determines the relative strength of these two mechanisms and thus the properties of $\omega\left(I_{\text {seg }}\right)$.

Figure 4 depicts stylized functions $w\left(I_{\text {seg }}\right)$ and $h\left(I_{\text {seg }}\right)$, reflecting their properties discussed above. The product of these two functions, relative earnings $\omega\left(I_{\text {seg }}\right)$, is also depicted in the figure. The position of the $\omega\left(I_{\text {seg }}\right)$ curve with respect to the $\omega=1$ line is crucial for the existence of equilibria, since in any interior equilibrium $\omega\left(I_{\text {seg }}^{e}\right)=1$. The slope of $\omega\left(I_{\text {seg }}\right)$ determines the stability of interior equilibria. In particular, negative slope of $\omega\left(I_{\text {seg }}\right)$ in the neighborhood of an interior equilibrium is necessary for its stability, since in such case any deviation from this equilibrium leads to switching of individuals that restores it. This is apparent from the figure, where arrows indicate the response of $I_{\text {seg }}$ in disequilibrium states. For example, given that $\omega\left(I_{\text {seg }}\right)$ is decreasing in $I_{\text {seg }}$ and 
$\omega\left(I_{\text {seg }}^{e}\right)=1$ due to the arbitrage condition, if the deviation within such neighborhood is such that $I_{\text {seg }}>I_{\text {seg }}^{e}$, then earnings of integrated minority become larger than those of segregated minority, that is, $\omega\left(I_{\text {seg }}\right)<1$. If this is the case, however, minority individuals switch to integrated social networks, thereby increasing $\omega\left(I_{\text {seg }}\right)$, until the initial equilibrium is restored. Similar argument explains stability for a deviation below $I_{\text {seg }}^{e}$. Given these properties of the earnings functions, I now establish the existence of a stable interior equilibrium defined by the arbitrage condition (AC).

Figure 4: Interior equilibrium of segregation

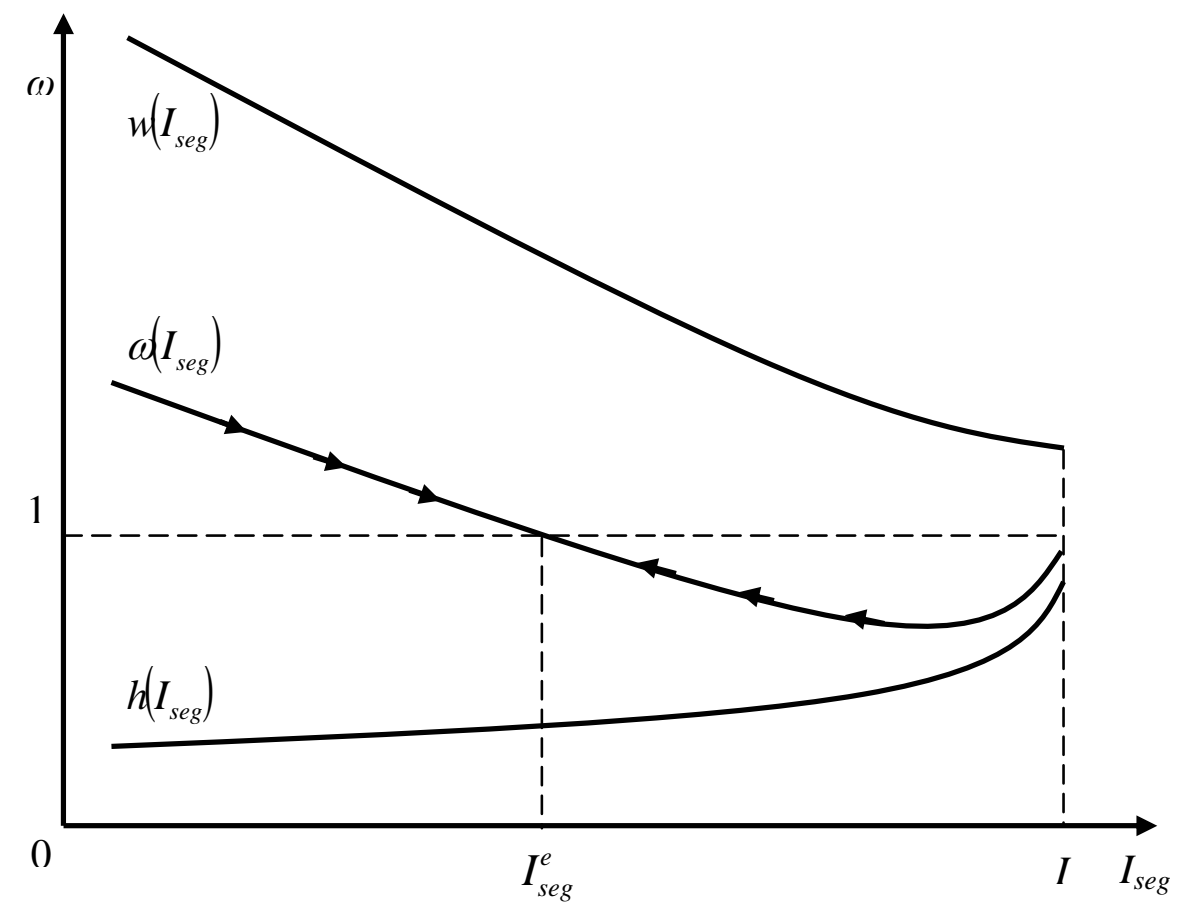

\section{Proposition 1}

There always exists some finite $\bar{\rho}>0$ such that for any finite $\rho>\bar{\rho}$ there exists a stable interior equilibrium $I_{\text {seg }}^{e} \in(0, I)$. Any interior equilibrium satisfies condition (IEC).

Proof in the Appendix. 
In particular, no stable interior equilibrium may exist if segregated and integrated labors are perfect substitutes. The reason is that in such case $W_{\text {seg }}=W_{\text {int }}$ and thus $\omega\left(I_{\text {seg }}\right)=h\left(I_{\text {seg }}\right)$, which is, as discussed above, monotonically increasing in $I_{\text {seg }}$. As a result, in any interior equilibrium, which must satisfy $\omega\left(I_{\text {seg }}\right)=1$, any disturbance such that $I_{\text {seg }}>I_{\text {seg }}^{e}\left(I_{\text {seg }}<I_{\text {seg }}^{e}\right)$ drives $\omega\left(I_{\text {seg }}\right)$ above (below) one, generating incentives for minority individuals to switch to segregation (integration). Due to monotonicity of $\omega\left(I_{\text {seg }}\right)$, a new equilibrium arises only after all minority individuals have switched to segregation (integration). On the other hand, if $\rho$ is very small, the substitution effect overrides the efficiency effect and segregation is the preferred choice for all minority individuals. In effect, $\rho$ has to be finite such that the substitution effect is operative but sufficiently large such that it is not excessively strong. That all interior equilibria must comply with the (IEC) condition is obvious from the fact that for $I_{\text {seg }}^{e} \in(0, I)$ and a finite $\rho$ it holds that $w\left(I_{\text {seg }}\right)>1 .^{22}$ Because in any equilibrium $\omega\left(I_{\text {seg }}^{e}\right)=1$, it must be that $h\left(I_{\text {seg }}\right)<1$, which is exactly the (IEC) condition. The next proposition discusses corner equilibria.

\section{Proposition 2}

There always exists some finite $\hat{\rho}>0$ such that for any finite $\rho<\hat{\rho}$ it holds that $I_{\text {seg }}=I$ is a stable equilibrium. Full segregation is also a stable equilibrium whenever condition (IEC) does not hold for $I_{\text {seg }}=I$, that is, $\delta>(J / I)^{\gamma}-1$. Full integration is never an equilibrium, formally, $I_{\text {seg }}^{e}>0$.

Proof in the Appendix.

The results stated in Proposition 2 are intuitive. If $\rho$ is sufficiently small, segregated labor is not easily substitutable in production and thus, given the smaller number of

${ }^{22}$ This can easily be verified noting that, since $I<J,\left.w\left(I_{\text {seg }}\right)\right|_{I_{\text {seg }}=I}=\left(\frac{\left(1+J^{\gamma}\right) J}{\left(1+I^{\gamma}\right) I}\right)^{\frac{1}{\rho}}>1$. 
minority people, minority individuals receive relatively high wage, which drives them all to segregate. Next, if (IEC) does not hold, the efficiency of social interaction of minority individuals is lower in integrated social networks than in segregated ones, $h\left(I_{\text {seg }}\right)_{I_{\text {seg }}=I}>1$, and, because $J>I$, under full segregation it also holds that $\left.w\left(I_{\text {seg }}\right)\right|_{I_{\text {seg }}=I}>1$, it must be that $\left.\omega\left(I_{\text {seg }}\right)\right|_{I_{\text {seg }}=I}>1$. That full integration is never an equilibrium follows from the very large incentives to segregate, and thus supply a very scarce type of labor, whenever the number of segregated individuals and thus the degree of segregation are very low.

Figure 5: Interior and corner equilibria of segregation

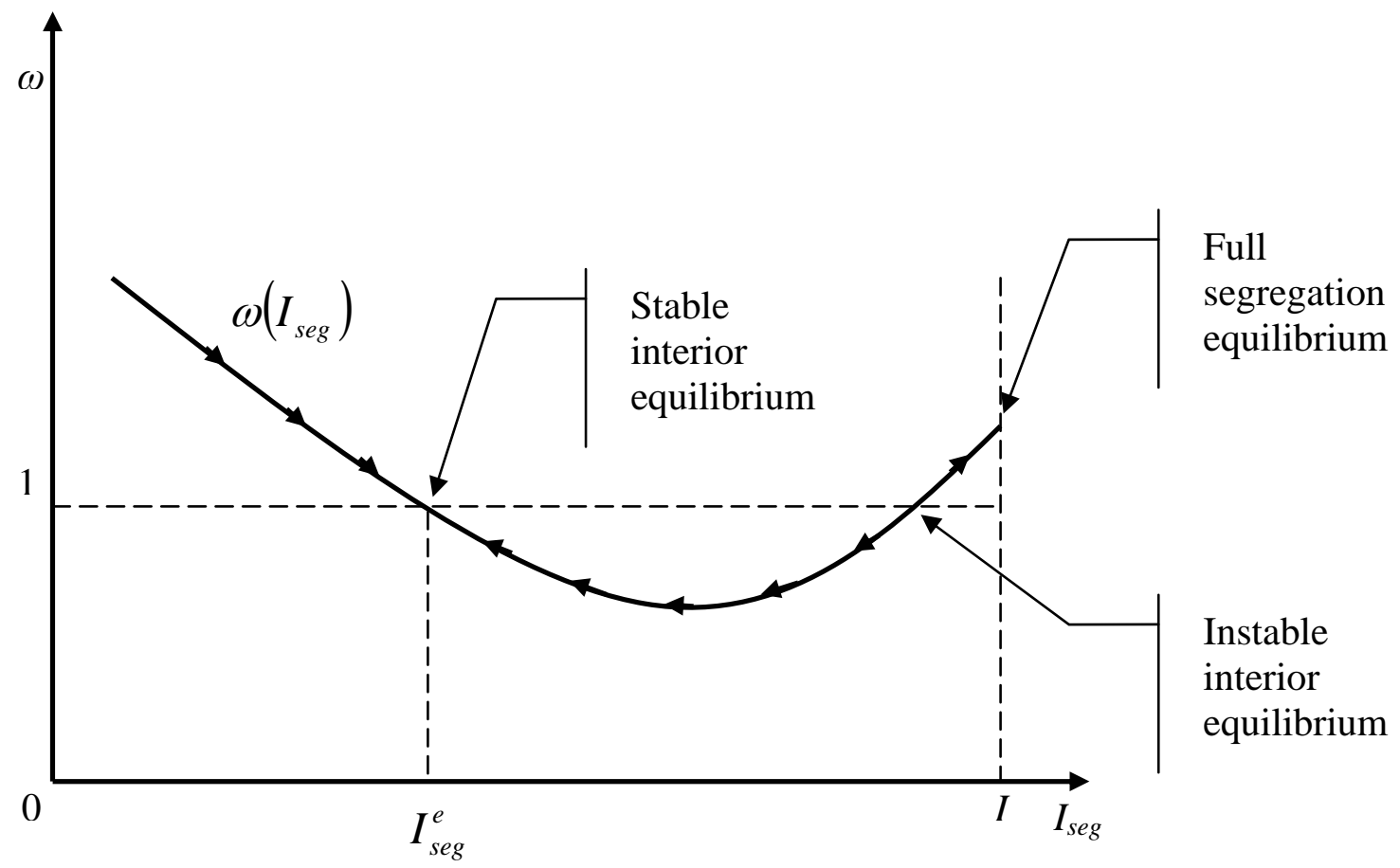

To fix the ideas, if the elasticity of substitution between segregated and integrated human capitals is large enough, at least one stable interior equilibrium exists in the economy. If this elasticity is small enough or condition (IEC) does not hold under full segregation, there exists a stable equilibrium of full segregation. On the other hand, complete desegregation is never an equilibrium in this model. An interesting question is whether there can be multiple segregation equilibria in the economy. The answer is yes. 
According to Proposition 1 there always exists an interior equilibrium for $\rho$ sufficiently large. But if condition (IEC) does not hold for $I_{\text {seg }}=I$ such that $\delta>(J / I)^{\gamma}-1$, then it is easy to see that $\omega\left(I_{\text {seg }}\right)_{I_{\text {seg }}=I}>1$ for any $\rho$ and a full segregation equilibrium exists as well. Figure 5 illustrates these equilibria.

\section{The ICT Revolution}

\subsection{The Level of ICT and its Role in the Model}

Let us now turn to the effects of the ICT revolution on the economy. As mentioned above, advancement of information and communication technologies improves the efficiency of exchanging and processing information. I conceptualize the level of ICT as the likelihood $\chi, 0<\chi \leq 1$, that ICT permits social interaction between two randomly chosen individuals who are not separated by segregation. Thus, this probability is a measure of the level of ICT. From the point of view of an individual it is exogenous. Advancement of ICT is operationalized as an increase in $\chi \cdot{ }^{23}$ It follows that, applying the law of large numbers and noting in (5.3a-c) that any chance to socially interact is valuable and thus taken, a segregated minority individual socially interacts with $I_{\text {seg }} \chi$ minority individuals who have chosen to segregate. Similarly, an integrated individual socially interacts with $I_{\text {int }} \chi$ integrated minority individuals and $J \chi$ majority individuals. ${ }^{24}$ Parameter $\chi$ is accordingly built into equations (5.3a-c), which yields the following modifications of the arbitrage condition (AC):

\footnotetext{
${ }^{23}$ It is assumed that ICT technologies symmetrically affect segregated and integrated social networks. This assumption serves the sake of exposition and has no influence on the main argument.

${ }^{24}$ One can now interpret $(1 /(1+\delta))^{\frac{1}{\gamma}}$ as the probability that two individuals with social distance $\delta$ can socially interact. For the same reasons as in the case of $\chi$, a majority individual interacts with

$(1 /(1+\delta))^{\frac{1}{\gamma}} I_{\text {int }}$ minority individuals and an integrated minority individual interacts with $(1 /(1+\delta))^{\frac{1}{\gamma}} J$ majority individuals. Note that in Section 5.3 it is implicitly assumed that $\chi=1$.
} 


$$
\left(\frac{\left(1+\left(I_{\mathrm{in}} \chi\right)^{\gamma}+\frac{1}{1+\delta}(J \chi)^{\gamma}\right) I_{\mathrm{int}}+\left(1+\frac{1}{1+\delta}\left(I_{\mathrm{in}} \chi\right)^{\gamma}+(J \chi)^{\gamma}\right) J}{\left(1+\left(I_{\text {seg }} \chi\right)^{\gamma}\right) I_{\text {seg }}}\right) \frac{1+\left(I_{\text {seg }} \chi\right)^{\gamma}}{1+\left(I_{\mathrm{in}} \chi\right)^{\gamma}+\frac{1}{1+\delta}(J \chi)^{\gamma}}=1 .
$$

It is worthwhile to note that introduction of $\chi$ into the model does not alter the integration efficiency condition (IEC). The reason is that $\chi$ affects segregated and integrated social networks symmetrically.

\subsubsection{Desegregation}

Having reformulated the arbitrage condition (AC) such that it implicitly defines $I_{\text {seg }}^{e}$ as a function of $\chi$, I am now equipped to study the effects of the ICT revolution on segregation.

\section{Proposition 3}

For any $\chi, 0<\chi \leq 1$, and any given $I_{\text {seg }}$ such that condition (IEC) holds, there always exists some finite $\tilde{\rho}>0$ such that for any finite $\rho>\tilde{\rho}$ it holds that $\partial \omega\left(I_{\text {seg }}, \chi\right) / \partial \chi<0$. If condition (IEC) does not hold at a given $I_{\text {seg }}$, $\partial \omega\left(I_{\text {seg }}, \chi\right) / \partial \chi \geq 0$.

Proof in the Appendix.

Proposition 3 states that if condition (IEC) holds and segregated and integrated efficient labors are good but imperfect substitutes, improvement in the level of ICT leads to a decrease of the ratio of segregated and integrated earnings and therefore generates incentives to desegregate. In particular, if for minority individuals integrated social networks are more efficient than segregated ones, that is, if condition (IEC) holds, ICT advancement increases the efficiency of integrated social networks more than that of segregated ones. A large enough elasticity of substitution $\rho$ secures that the resulting ICT-driven increase of individual supply of segregated relative to integrated labor is not reversed by the negative effect of this increase on the relative price of segregated labor at 
the aggregate level. Corollaries 1a, 1b, and 1c straightforwardly follow from Proposition 3:

\section{Corollary $1 a$}

For any stable interior equilibrium $I_{\text {seg }}^{e}$ there always exists a finite $\tilde{\rho}$ such that for any finite $\rho>\tilde{\rho}$ an increase in $\chi$ instigates desegregation such that the equilibrium level of segregation $I_{\text {seg }}^{e}$ decreases.

\section{Corollary $1 b$}

If $I_{\text {seg }}^{e}=I$ is a corner equilibrium and satisfies condition (IEC), an increase in $\chi$ decreases $\left.\omega\left(I_{\text {seg }}\right)\right|_{I_{\text {seg }}=I}$ and

i) leaves the economy at $I_{\text {seg }}^{e}=I$, as long as $\chi$ is such that $\left.\omega\left(I_{\text {seg }}\right)\right|_{I_{\text {seg }}=I} \geq 1$

ii) causes desegregation, if the increase in $\chi$ drives $\left.\omega\left(I_{\text {seg }}\right)\right|_{I_{\text {seg }}=I}$ below one.

\section{Corollary $1 c$}

Whenever condition (IEC) is not satisfied it holds that $\partial \omega\left(I_{\text {seg }}, \chi\right) / \partial \chi>0$ and therefore the degree of segregation remains unchanged in any corner equilibrium of full segregation.

These corollaries describe the effects of ICT improvement on the degree of segregation in the economy. In particular, whenever the economy starts in an interior equilibrium and Black and White efficient labors are relatively well substitutable, ICT improvement brings about desegregation. If the economy starts in a corner equilibrium of full segregation, however, the (IEC) condition is not necessarily satisfied and thus ICT improvement may increase earnings in segregated as compared to integrated social networks, thereby perpetuating full segregation. Moreover, even if the (IEC) condition is satisfied in the corner equilibrium, ICT improvement instigates desegregation only with a 
delay, as it first needs to close the initial gap between segregated and integrated earnings. ${ }^{25}$ As soon as this occurs, however, desegregation is extensive.

Figure 6 illuminates the effects of ICT on the segregation equilibria. From the initial state A, an increase in $\chi$ shifts the $\omega\left(I_{\text {seg }}\right)$ curve down to B. Such shift causes desegregation to $I_{\text {seg }}^{B}$, if the economy starts in an interior equilibrium $I_{\text {seg }}^{A}$. If full segregation is the initial state, however, no desegregation occurs. Further increase of $\chi$ shifts the $\omega\left(I_{\text {seg }}\right)$ curve down to $\mathrm{C}$ and the interior equilibrium shifts from $I_{\text {seg }}^{B}$ to $I_{\text {seg }}^{C}$. Unlike in the previous case, however, the shift of the $\omega\left(I_{\text {seg }}\right)$ schedule is so large as to cause desegregation from the full segregation equilibrium to the interior equilibrium $I_{\text {seg }}^{C}$.

Figure 6: The effects of $\chi$ on equilibrium segregation

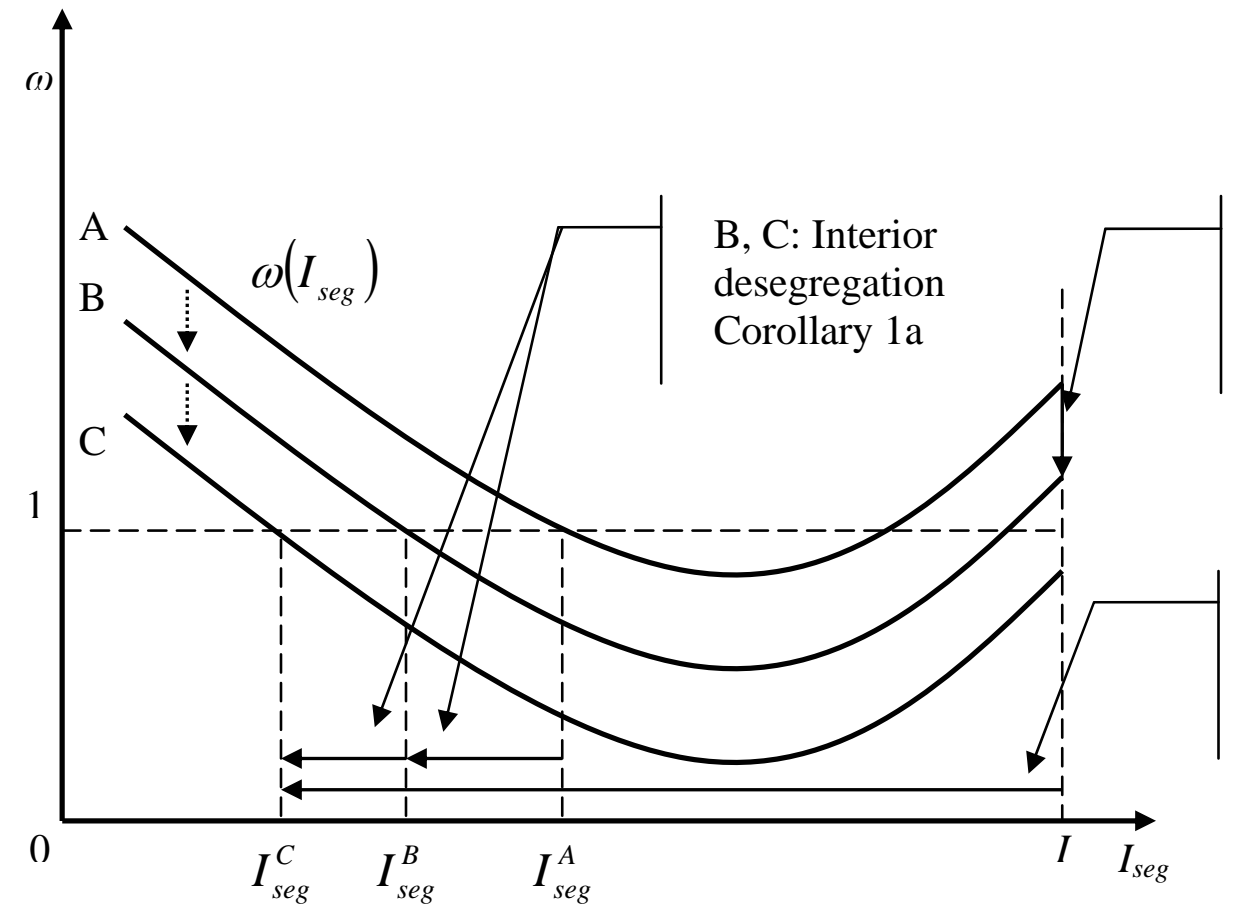

B: No desegregation Corollary 1b (i)

C: Extensive desegregation Corollary 1b (ii)

\footnotetext{
${ }^{25}$ Earnings gap $\omega\left(I_{\text {seg }}\right)_{I_{\text {seg }}=I}>1$ is a sufficient condition for a stable equilibrium of full segregation. If $\partial\left(W_{\text {seg }} / W_{\text {int }}\right) /\left.\partial I_{\text {seg }}\right|_{I_{\text {seg }}=I}<0$ and the condition (IE) holds, then $I_{\text {seg }}=I$ is a stable corner equilibrium even without an earnings gap, that is, if $\omega\left(I_{\text {seg }}\right)_{I_{\text {seg }}=I}=1$. In such knife-edge case, ICT improvement instigates immediate desegregation from $I_{\text {seg }}=I$.
} 
The next proposition states further results of the effects of $\chi$ on the economy:

\section{Proposition 4}

Whenever $\chi=0$, the only stable equilibrium is that of full segregation, $I_{\text {seg }}^{e}=I$. Whenever (IEC) holds, there always exists a finite $\hat{\rho}>0$ and $\hat{\chi} \in(0,1)$ such that for any $\rho>\hat{\rho}$ :

(i) For any $\chi<\hat{\chi}$ full segregation is a stable equilibrium,

(ii) For any $\chi>\hat{\chi}$ full segregation is not a stable equilibrium and there exists a stable interior segregation equilibrium, $I_{\text {seg }}^{e} \in(0,1)$.

Proof in the Appendix.

Figure 7: The effects of $\chi$ on the existence of interior and corner equilibria

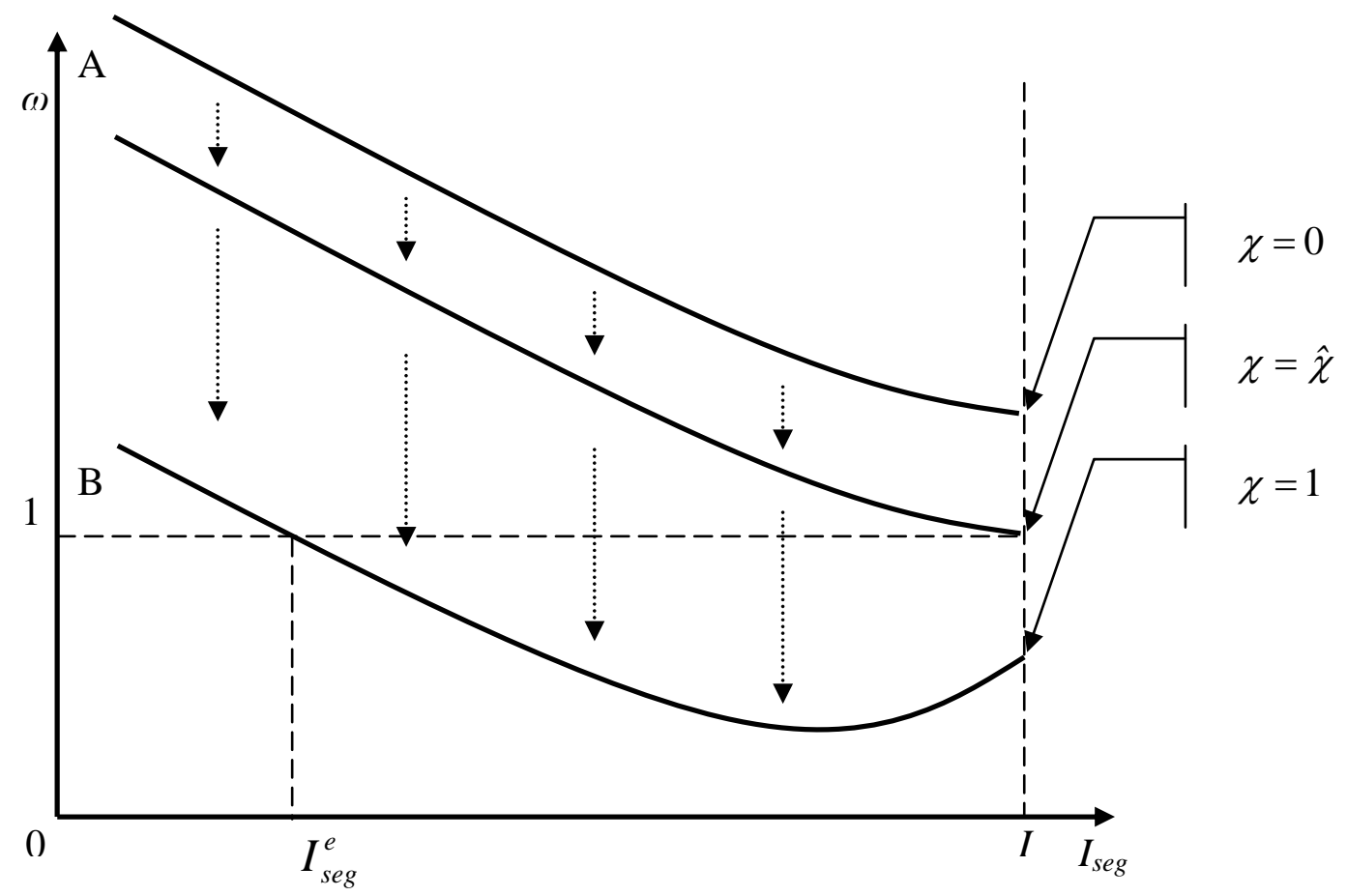

Figure 7 depicts stylized patterns of $\omega\left(I_{\text {seg }}\right)$ as determined by the level of ICT $\chi$ and elucidates the results depicted in Proposition 4. If $\chi=0$, the only mechanism that drives the choice between segregation and integration is the choice between segregated and 
integrated wages. Because minority is smaller than majority, segregated wage is higher than integrated, and the more so the fewer minority individuals segregate. Therefore, the curve A for $\chi=0$ is downward sloping and always above the line $\omega=1$. Clearly, the only equilibrium is that of full segregation. Full segregation remains a stable equilibrium until $\chi$ reaches $\hat{\chi}$. After this point, for $\chi \in(\hat{\chi}, 1)$ depicted by curve $\mathrm{B}$, full segregation is not an equilibrium and the economy desegregates towards an interior equilibrium $I_{\text {seg }}^{e}$.

Proposition 4 thus offers an answer why the segregation of the period before the 1970s has been replaced by desegregation thereafter. If the level of ICT is relatively low, the efficiency benefits of integration are minor compared to the wage advantage minority individuals incur if they segregate. As soon as the threshold level of ICT $\hat{\chi}$ is attained, however, the efficiency benefits of integration outweigh this wage advantage and thereby trigger desegregation, which continues until equilibrium between the efficiency benefits of integration and the wage advantage of segregation is restored.

\subsubsection{Inter-Ethnic Earnings Inequality}

Besides affecting equilibrium degree of segregation in the economy, improvements in ICT affect interethnic earnings inequality as well. Primarily, they affect the relative efficiency of segregated and integrated social networks. Next, the resulting changes in supplies of efficient labors affect relative wages of segregated and integrated labors. Finally, given the changes in earnings, switching between segregated and integrated social networks occurs and further affects the efficiencies of human capital acquisition and wages. Assuming that wages respond relatively quickly, I denote the first two responses the short run effect and the response that involves switching between segregation and integration the long run effect. Propositions $5 a$ and $5 b$ state short run results:

\section{Proposition $5 a$}

For any finite $\rho$ and a given $I_{\text {seg }} \in[0, I]$, an increase in $\chi$ leads to a larger increase in the earnings of majority individuals than integrated minority 
individuals. That is, $\partial \Omega_{j} /\left.\partial \chi\right|_{I_{\text {seg }}}>\partial \Omega_{i, \text { int }} /\left.\partial \chi\right|_{I_{\text {seg }}}$.

\section{Proposition $5 b$}

For any interior equilibrium, there always exists some finite $\tilde{\rho}>0$ such that for any finite $\rho>\tilde{\rho}$ and any given $I_{\text {seg }} \in[0, I]$ an increase in $\chi$ increases the earnings of majority individuals more than those of segregated minority individuals, that is, $\partial \Omega_{j} /\left.\partial \chi\right|_{I_{\text {seg }}}>\partial \Omega_{i, \text { seg }} /\left.\partial \chi\right|_{I_{\text {seg }}}$.

Proofs in Appendix.

From Proposition 5a we see that the ICT revolution increases earnings inequality between integrated minority and majority individuals in the short run. The reason is that the relatively small number of integrated minority individuals, as compared to the number of majority individuals, and the social distance between minority and majority individuals constrain the network benefits for integrated minority individuals. Because integrated minority and majority individuals earn the same wage, this efficiency effect fully determines the effects of ICT improvement on minority-majority inequality in integrated social networks. As depicted in Proposition 5b, earnings gap between segregated minority individuals and majority individuals increases as well, if the substitutability of segregated and integrated efficient labors is sufficiently high. Under that condition, the substitution mechanism does not offset the efficiency mechanism through which ICT improvement works in favor of majority individuals, similarly as in Proposition 3. Condition (IEC) is not necessary for these results, because minority is always less efficient than majority in human capital acquisition.

Can, however, desegregation and increasing interethnic inequality coexist in the long run, after desegregation takes place and a new segregation equilibrium arises? Clearly, desegregation reduces the earnings gap between integrated minority individuals and majority individuals, as it improves the relative efficiency of the former in human capital acquisition. ${ }^{26}$ Because desegregation continues until earnings of segregated and

\footnotetext{
${ }^{26}$ This follows straightforwardly from comparison of technologies (3b) and (3c).
} 
integrated minority are equalized, desegregation reduces the earnings gap between segregated minority and majority as well. In effect, desegregation works against the aggravating effects of the ICT improvement on interethnic earnings inequality. The following proposition states that for sufficiently large $J / I$, the direct effect of ICT revolution on interethnic earnings inequality outweighs the indirect one that works through desegregation.

\section{Proposition 6}

For any interior equilibrium, there always exists some $\bar{y}>0$ such that for all $J / I>\bar{y}$ and $I_{\text {seg }} \in(0,1]$ an improvement in the level of ICT $\chi$ causes desegregation and increases interethnic earnings inequality in the long run, that is, $\partial \Omega_{j} / \partial \chi>\partial \Omega_{i, \text { seg }} / \partial \chi$ and $\partial \Omega_{j} / \partial \chi>\partial \Omega_{i, \text { int }} / \partial \chi$.

Proof in the Appendix.

Thus, if the number of majority individuals is sufficiently larger than the number of minority individuals, ICT improvement increases the relative efficiency of majority individuals in skill acquisition so strongly that ICT-driven desegregation does not reverse the tendency of ICT improvement to increase minority-majority earnings inequality. ${ }^{27}$

To summarize this section, in any interior equilibrium ICT improvement in the short run generates incentives to desegregate and increases interethnic earnings inequality. In the long run, minority people desegregate and thereby attenuate earnings inequality. If majority is sufficiently larger than minority, however, the direct effect of ICT improvement on inequality outweighs the indirect long-run effect and desegregation and increasing earnings inequality both occur in the long run.

${ }^{27}$ In particular, $\partial \Omega_{j} / \partial \chi>\partial \Omega_{i, \text { seg }} / \partial \chi$ and $\partial \Omega_{j} / \partial \chi>\partial \Omega_{i, \text { int }} / \partial \chi$ whenever $\frac{\partial I_{\text {int }} / I_{\text {int }}}{\partial \chi / \chi}<\left(\frac{J}{I_{\text {int }}}\right)^{\gamma}-1$ or $I_{\text {int }}=0 . \frac{\partial I_{\text {int }} / I_{\text {int }}}{\partial \chi / \chi}$ can be interpreted as the elasticity of desegregation with respect to ICT advancement. 


\section{Discussion}

\subsection{Segregation and Earnings Inequality}

In this paper I highlight the role of advancement of information and communication technologies, such as that pertaining to the ICT revolution, in shaping the incentives of minority people to desegregate and in determining interethnic earnings inequality. I argue that the ICT revolution under some conditions increases the incentives of minority to switch to integrated social networks by improving the efficiency of skill acquisition in these social networks relative to segregated ones. These conditions are the more likely to be satisfied the smaller the social distance, the larger the majority as compared to the minority, and/or the smaller the degree of segregation. If the economy is in an interior equilibrium where some minority people integrate and some segregate and if efficient labors of integrated and segregated people are relatively good substitutes, people react to these changed incentives by switching to integrated social networks, that is, desegregating. Desegregation continues until a new segregation equilibrium is restored through the substitution mechanism that depresses the relative wage of integrated individuals until earnings of segregated and integrated minority are equalized.

In the case of complete segregation, however, minority individuals remain segregated even if ICT improvement enhances the efficiency of skill acquisition in integrated social networks relative to segregated ones until the advancement of ICT technologies is large enough to wipe out the initial efficiency advantage of living in segregated social networks. This finding is particularly interesting from the perspective of the findings of Cutler et al. (1999) that in regions with extraordinarily high degrees of segregation desegregation was limited.

ICT improvement increases earnings inequality between integrated minority individuals and majority individuals. The reason is that the efficiency effect favors majority individuals, who are less hurt by social distance as they interact with a relatively small number of socially distant integrated minority individuals. In contrast, integrated minority individuals interact with a relatively large number of socially distant majority individuals. 
Similarly, ICT advancement favors majority individuals relative to segregated minority individuals, whose social networks are limited in size. Earnings gap widens whenever labors of segregated and integrated individuals are relatively good substitutes, such that an increase in efficiency is not offset by the substitution mechanism that depresses the wage of integrated individuals. In the long run, desegregation works to attenuate the first order effects of ICT advancement on earnings inequality depicted above. Whenever the efficiency advantage of the majority is large enough, however, desegregation does not reverse the main mechanisms through which ICT advancement facilitates desegregation of minority individuals and increases minority-majority earnings inequality.

\subsection{The Reversal of the 1970s}

Based on the aforementioned arguments one can explain the history of segregation and Black-White earnings inequality over the last quarter of the $20^{\text {th }}$ Century in the United States and the concurrence of desegregation and increasing interethnic inequality in particular. Proposition 4 sheds some light on the earlier periods of the $20^{\text {th }}$ Century characterized by increasing segregation of the Black minority and offers an answer to the question what caused the segregation reversal in the 1970s. In particular, I argue that because information and communication technologies were embryonic in the early decades of the $20^{\text {th }}$ century, minority individuals had no incentives to integrate for two reasons. First, upon integration they would be hurt by the increased competition of the larger number of majority individuals on the labor market through the substitution mechanism. Second, the social distance between them and the majority would disadvantage them in integrated social networks in terms of efficiency of skill acquisition. Any migration in that period, driven by these incentives to segregate, increased the aggregate level of segregation.

The gradual advancement of ICT technologies and in particular their massive development since the 1970s, however, offers an explanation of the segregation reversal that occurred at the same time. The rapid increase of the use of communication over the telephone since the 1970s and especially the revolutionary development of the personal 
computer since the 1980s and mobile telephony and the Internet since the late 1980s, I argue, significantly increased the efficiency of social interaction in larger integrated social networks, as compared to typically smaller segregated social networks. This improvement surpassed the threshold level of ICT below which segregation is superior to integration for minority individuals and stimulated the Black minority to increase their investment in integrated social networks to reap the benefits of the ICT advancement.

\subsection{The Left-Behinds}

While ICT advancement fosters desegregation, certain factors may inhibit or preclude ICT-driven desegregation. First, ICT advancement may not be enough to trigger desegregation in extraordinarily segregated social networks or neighborhoods. The reason is that there the ICT advancement may be insufficient to tip the efficiency tradeoff in favor of integration for an extended period of time, until certain threshold level of ICT is achieved (Proposition 4). Furthermore, ICT-advancement does not favor interaction in integrated social networks whenever social distance between minority and majority individuals is relatively large such that condition (IEC) does not hold, since then the minority does not benefit from interaction with majority individuals in integrated social networks. This may explain the high levels of segregation of recent immigrants, who are typically socially more distant to the majority individuals than incumbent minority individuals. $^{28}$

\subsection{Social Interaction and the Neighborhood}

Given the dramatic development of ICT that annihilates geographical distances as concerns exchange of information, a valid question is whether advancement of ICT eventually makes the neighborhood obsolete. Indeed, there are scholars that suggest that advancement of ICT renders the location of an individual in geographical space immaterial. ${ }^{29}$ In this vein, Nie and Erbring (2000) argue that newer technologies of social

\footnotetext{
${ }^{28}$ See Cutler et al. (2005)

${ }^{29}$ See e.g. Toffler (1980), Naisbitt (1995), and Negroponte (1995).
} 
interaction such as the Internet replace older ones, including face-to-face social interaction, which is by and large locally embedded.

In contrast, other scholars, including Gaspar and Glaeser (1996), Robinson et al. (2000), Hampton and Wellman (2000), and Katz et al. (2001), argue that newer and older technologies of social interaction are complementary. Gaspar and Glaeser (1996) provide a theoretical explanation how ICT advancement gives rise to more social interaction facilitated by both new and old technologies through lowering costs of creating and maintaining a relationship, offering several pieces of evidence to support their theory. Robinson et al. (2000) and Hampton and Wellman (2000) evidence that Internet users are no less active in using media or socializing offline than nonusers. Hampton and Wellman also find that Internet users are acquainted with three times as many of their neighbors than nonusers. Katz et al. (2001) report that Internet users visit friends more often and telephone them more frequently.

Based on this evidence it can be argued that newer and older ICT technologies are complements in social interaction and that advancement of ICT does not make the neighborhood and face-to-face social interaction therein obsolete. In fact, the abovementioned evidence suggests that the importance of the neighborhood increases hand in hand with ICT advancement. Given this complementarity, ICT advancement does not break the link between social interaction and individual location. In particular, ICT advancement not only generates the patterns of (de-)segregation between integrated and segregated social networks discussed in previous sections, but these patterns are reflected in (de-)segregation between segregated and integrated neighborhoods, as evidenced by empirical literature reviewed above.

\section{Conclusion}

This paper provides an account of the role of the ICT revolution in the history of desegregation and increasing interethnic earnings inequality in the $20^{\text {th }}$ Century in the United States. It explains why ICT contributes to desegregation and how it fuels earnings 
inequality. It offers an answer why segregation reversal occurred after the 1970s, why extraordinarily segregated neighborhoods remained so, and why recent immigrants experienced high levels of segregation throughout the period. The importance of social interaction in human capital acquisition, social distances, and relative group sizes on these developments are highlighted.

Further theoretical studies should focus on the determination of the level of ICT and formalize the ICT revolution as an outcome of human effort. It would also be interesting to study the direction of ICT innovation in the multiethnic world where information and communication technologies are specific to ethnic groups. Finally, from the empirical perspective, we need further accounts of desegregation and interethnic earnings inequality, e.g. in Europe. 


\section{References}

Allen, Beth, "Some Stochastic Processes of Interdependent Demand and Technological Diffusion of an Innovation Exhibiting Externalities among Adopters,” International Econoic Review, Vol. 23, (1982), pp. 595-607.

Altonji, J. and R. Blank, "Race and Gender in the Labor Market", in eds. O. Ashenfelter and D. Card, Handbook of Labor Economics, Volume 3c, (1998).

Bala, Vanketash and Sanjeev Goyal, "Learning from Neighbors," Review of Economic Studies, Vol. 65, (1998), pp. 595-621.

Bell, W., “A Probability Model for the Measurement of Ecological Segregation,” Social Forces, Vol. 32, (1954), pp. 357-64.

Borjas, George J., “Long-Run Convergence of Ethnic Skill Differentials: The Children and Grandchildren of the Great Migration,” Industrial and Labor Relations Review, (July 1994), pp. 553-573.

Bound, John and Richard B. Freeman, "What Went Wrong? The Erosion of Relative Earnings and Employment among Young Black Men in the 1980s,” Quarterly Journal of Economics, Vol. 107, (1992), pp. 201-32.

Bourdieu, Pierre, "Forms of Capital," in Handbook of Theory and Research for the Sociology of Education, John G. Richardson, ed. Westport, CT: Greenwood Press, (1986), pp. 241-60.

Card, David and Thomas Lemieux, "Changing Wage Structure and Black-White Wage Differentials,” The American Economic Review, Vol. 84, (1996), pp. 29-33.

Cole, J., Surveying the Digital Future, Los Angeles: UCLA Center for

Telecommunication Policy, (www.ccp.ucla.edu), (2000).

Coleman, J. S., "Social capital in the creation of human capital," American Journal of Sociology, Vol. 94, (1988), pp. S95-S120.

Coleman, J.S., Foundations of Social Theory. Cambridge, MA: Harvard University Press, (1990).

Conley, Timothy and Christopher Udry, "Learning about a New Technology: Pineapple in Ghana,” mimeo, Yale University, (March, 2002).

Cutler, David M., Edward L. Glaeser and Jacob L. Vigdor, "The Rise and Decline of the American Ghetto” The Journal of Political Economy, Vol. 107, No. 3. (June, 1999), pp. 455-506.

Cutler, David M., Edward L. Glaeser and Jacob L. Vigdor, "Is the Melting Pot Still Hot? Explaining the Resurgence of Immigrant Segregation” Discussion Paper No. 2071, Harvard Institute for Economic Research, Harvard University, (May 2005).

Donohue, John J. III and James Heckman, "Continuous Versus Episodic Change: The Impact of Civil Rights Policy on the Economic Status of Blacks,” Journal of Economic Literature, Vol. XXIX, (December, 1991), pp. 1603-1643.

DuBois, W. E. Burghardt, “The Philadelphia Negro: A Social Study,” Philadelphia: University of Pennsylvania Press, (1899)

Duncan O. D. and B. Duncan, “A Methodological Analysis of Segregation Indexes,” American Sociological Review, Vol. 20, (1955), pp. 210-217.

Ellison, Glenn and Drew Fudenberg, “Rules of Thumb for Social Learning,” Journal of Political Economy, Vol. 101, (1993), pp. 93-125. 
Ellison, Glenn and Drew Fudenberg, "Word-of-Mouth Communication and Social Learning,” Quarterly Journal of Economics, Vol. 110, No. 1, (February, 1995), pp. 8397.

Farley, Reynolds and William H. Frey, "Changes in the Segregation of Whites from Blacks During the 1980s: Small Steps toward a More Racially Integrated Society,” American Sociological Review, Vol. 59, (1994), pp. 23-45.

Feldman, Maryann P., "The Internet Revolution and the Geography of Innovation," International Social Science Journal, Vol. 171, (2002), pp. 47-56.

Foster, Andrew D. and Mark R. Rosenzweig, "Learning by Doing and Learning from Others: Human Capital and Technical change in Agriculture,” Journal of Political Economy, Vol. 103, No. 6, (1995), pp. 1176-1209.

Fraser, Angus, The Gypsies, Blackwell, Oxford, (1992).

Frey, Williams H. and Reynolds Farley, Latino, Asian, and Black Segregation in U.S. Metropolitan Areas: Are Multi-ethnic Metros Different?” Demography, Vol. 33, No. 1, (February 1996), pp. 35-50.

Gaspar, Jess and Edward L. Glaeser, "Information Technology and the Future of Cities,” Journal of Urban Economics, Vol. 43, (1998), pp. 136-156.

Glaeser, Edward L., David Laibson, and Bruce Sacerdote, “An Economic Approach to Social Capital,” The Economic Journal, Vol. 112, (November, 2002), pp. 437-458.

Hampton, K. and B. Wellman, "Examining Community in the Digital Neighborhood: early Results from Canada’s Wired Suburb,” in Digital Cities: Experiences, Technologies, and Future Perspectives, ed. T. Ishida and K. Isbister, Heidelberg, Germany: Springer-Verlag, (2000), pp. 475-92.

Heckman, James J. and Brook S. Payner, "Determining the Impact of Federal Antidiscrimination Policy on the Economic Status of Blacks: A Study of South Carolina,” The American Economic Review, Vol. 79, No. 1, (March, 1989) pp. 138-177.

Hofstede, Geert H., "Culture's Consequences: International Differences in Work-related Values. Beverly Hills,” California: Sage Publications, (1980).

Juhn, Chinhui, Kevin M Murphy, and Brooks Pierce, “Accounting for the Slowdown in Black-White Wage Convergence," in: Marvin H Kosters, ed., Workers and their Wages, Washington DC: AEI Press, (1991).

Katz, J.E., R. Rice, and P. Aspden, "The Internet, 1995-2000: Access, Civic Involvement, and Social Interaction,” Special Issue of American Behavioral Scientist, ed. B. ellman and C. Haythorn-Waite, (2001).

Kraus, V. and R.W. Hodge, Promises in the Promised Land, N.Y.: Greenwood, (1990). Kraut, R., M. Patterson, V. Lundmark, S. Kiesler, T. Mukophadhyay, and W.

Scherlis, "Internet Paradox: A Social Technology that Reduces Social Involvement and Psychological Well-being?” American Psychology, Vol. 53, (1998), pp. 1011-31.

Lazear, Edward P., "Culture and Change,” The Journal of Political Economy, Vol. 107, No. 6, (1999), pp. 95-126.

Lin, Nan, “Building a Network Theory of Social Capital”, Connections, Vol. 22(5.1), (1999), pp. 28-51.

Loury, Glenn C., “A dynamic theory of racial income differences.” pp. 153-186 in P.A. Wallace and A. Le Mund, eds., Women, minorities, and employment discrimination. Lexington, MA: Lexington Books, (1977). 
Lucas, Robert E., Jr., “On the Mechanics of Economic Development,” Journal of Monetary Economics, Vol. 22, (1988), pp. 3-42.

Massey, Douglas S. and Nancy A. Denton, "Trends in the Residential Segregation of Blacks, Hispanics, and Asians,” American Sociological Review, Vol. 52, (1987), pp. 802-825.

Massey, Douglas S. and Nancy A. Denton, American Apartheid: Segregation and the Making of the Underclass, Cambridge, MA.: Harvard University, (1993).

Munshi, Kaivan, "Social Learning in a Heterogeneous Population: Technology Diffusion in the Indian Green Revolution,” Forthcoming. Journal of Development Economics, (2002).

Myrdal, Gunnar, An American Dilemma: The Negro Problem and Modern Democracy, New York: Harper and Row, (1944).

Naisbitt, R., The Global Paradox, Avon Books, New York, (1995).

Negroponte, N., Being Digital, Vintage Books, New York, (1995).

Neumark, David and Wendy A. Stock, "The Effects of Race and Sex Discrimination Laws,” Working Paper 8215, National Bureau of Economic Research, (April, 2001).

Nie, N.H., and L. Ebring, Internet and Society: A Preliminary Report, Stanford, CA, Institute for Quantitative Studies in Sociology, (2000).

Poole, Willard C., Jr., "Distance in Sociology,” The American Journal of Sociology, Vol. 33, No. 1. (Jul., 1927), pp. 99-104.

Rees, Albert and George P. Schultz, "Workers and Wages in an Urban Labor Market," Urban Studies, Vol. 9, No. 1 (February, 1972), pp. 130-132.

Robinson, J.P., M. Kestnbaum, A. Neustadtl, A. Alvarez, "IT, the Internet, and Time Displacement," Paper presented at Annual Meeting of American Association of Public Opinion Research, Portland, OR, (May, 2000)

Schuman, H. and L. Bobo, "Survey-Based Experiments on White Racial Attitudes Towards Residential Integration,” American Journal of Sociology, Vol. 94, (1988), pp. 273-99.

Schuman, H., C. Steeh, and L. Bobo, Racial Attitudes in America: Trends and Interpretations, Cambridge: Harvard University Press, (1985).

Sowell, T., Race and Culture: A World View, Basic Books, (1994).

Taeuber, Karl E. and Alma F. Taeuber, Negroes in Cities: Residential Segregation and Neighborhood Change, Chicago, IL: Aldine, (1965)

Toffler, A., The Third Wave, Bantam Books, New York, (1980).

Uslaner, E., "The Internet and Social Capital”, Communications of the Annals of Computing Machinery, Vol. 43, (Dec. 2000), pp. 60-64

Wellman, Barry, "Physical Place and Cyberplace: Changing Portals and the Rise of Networked Individualism,” International Journal of Urban and Regional Research, Forthcoming, (2001).

Wellman, Barry, Janet Salaff, Dimitrina Dimitrova, Laura Garton, Milena Gulia, Caroline Haythornthwaite, "Computer Networks as Social Networks: Collaborative Work, Telework, and Virtual Community,” Annual Review of Sociology, Vol. 22, (1996), pp. 213-238. 


\section{Appendix}

\section{Proof of Proposition 1}

Let us first state and prove two lemmas:

\section{Lemma 1}

There exists some $\bar{\rho}>0$ such that for any $\rho>\bar{\rho}$ it holds that $\omega\left(I_{\text {seg }}\right)<1$ for some $I_{\text {seg }} \in(0, I)$.

Proof: We know that there always exists $I_{\text {seg }} \in(0, I)$ that satisfies condition (IEC), that is, $\quad H_{i, \text { seg }}<H_{i \text {,int }}$. Combining (4a) and (4b) to obtain $\frac{W_{\text {seg }}}{W_{\text {int }}}=\left(\frac{\left(1+I_{\text {int }}^{\gamma}+\frac{1}{1+\delta} J^{\gamma}\right) I_{\text {int }}+\left(1+\frac{1}{1+\delta} I_{\text {int }}^{\gamma}+J^{\gamma}\right) J}{\left(1+I_{\text {seg }}^{\gamma}\right) I_{\text {seg }}}\right)^{\frac{1}{\rho}}$ and recalling that $I_{\text {int }}=1-I_{\text {seg }}$, it is straightforward to see that $\partial\left(W_{\text {seg }} / W_{\text {int }}\right) / \partial \rho<0$ and $\underset{\rho \rightarrow \infty}{\operatorname{Lim}}\left(W_{\text {seg }} / W_{\text {int }}\right)=1$ for any given $I_{\text {seg }}>0$. Thus, $W_{\text {seg }} / W_{\text {int }}$ can be arbitrarily close to one for large enough $\bar{\rho}$ and is closer for all $\rho>\bar{\rho}$. Such $\bar{\rho}$ is implicitly defined by: $\frac{H_{i, \text { seg }}}{H_{i, \text { int }}}\left(\frac{H_{i, \text { int }} I_{\text {int }}+H_{j} J}{H_{i, \text { seg }} I_{\text {seg }}}\right)^{\frac{1}{\rho}}=1$ and it is straightforward to see that it always exists. Therefore $\omega\left(I_{\text {seg }}\right) \equiv \frac{W_{\text {seg }}}{W_{\text {int }}} \frac{H_{i, \text { seg }}}{H_{i, \text { int }}}<1$ for some $I_{\text {seg }} \in(0, I)$ and all $\rho>\bar{\rho}$. This proves Lemma 1 .

\section{Lemma 2}

Denote $I_{\text {seg }}^{1}$ such $I_{\text {seg }} \in(0, I)$ where $\omega\left(I_{\text {seg }}^{1}\right)<1$. For any finite $\rho>0$ there exists $I_{\text {seg }}<I_{\text {seg }}^{1}$ such that $\omega\left(I_{\text {seg }}\right)>1$.

Proof: From the equation for $W_{\text {seg }} / W_{\text {int }}$ in the proof of Lemma 1 it is easy to see that $\operatorname{Lim}_{I_{\text {seg }} \rightarrow 0}\left(W_{\text {seg }} / W_{\text {int }}\right)=\infty$ and $\partial\left(W_{\text {seg }} / W_{\text {int }}\right) / \partial I_{\text {seg }}<0$ for any $I_{\text {seg }} \in(0, I)$. It follows that $W_{\text {seg }} / W_{\text {int }}$ can be arbitrarily large for some $I_{\text {seg }}$ small enough and in particular for some $I_{\text {seg }}<I_{\text {seg }}^{1}$. Because $H_{i, \text { seg }} / H_{i, \text { int }}$ is obviously positive (and finite) for any $I_{\text {seg }} \in[0, I]$, this implies that $\omega\left(I_{\text {seg }}\right)$ is larger than 1 for some $I_{\text {seg }} \in[0, I]$ and for some $I_{\text {seg }}<I_{\text {seg }}^{1}$ in particular. This proves Lemma 2. 
Now, since $\omega\left(I_{\text {seg }}\right)$ is continuous in $I_{\text {seg }}$ for any $I_{\text {seg }} \in(0, I)$ and continuous from the right at $I_{\text {seg }}=0$, Lemma 1 and Lemma 2 imply that there exists some $\bar{\rho}>0$ as defined in the proof of Lemma 1 such that for any $\rho>\bar{\rho}$ there must be $I_{\text {seg }} \in(0, I)$ where $\omega\left(I_{\text {seg }}\right)=1$ and $\omega\left(I_{\text {seg }}\right)$ has a negative slope. But these two conditions make it a stable equilibrium. Because it always holds that $W_{\text {seg }} / W_{\text {int }}>1$ and at an interior equilibrium $\omega\left(I_{\text {seg }}\right)=1$, it must be that $H_{i, \text { seg }} / H_{i, \text { int }}<1$, which is the (IEC) condition.

\section{Proof of Proposition 2}

If $\left.\omega\left(I_{\text {seg }}\right)\right|_{I_{\text {seg }}=I}=\left(\frac{\left(1+J^{\gamma}\right) J}{\left(1+I^{\gamma}\right) I}\right)^{\frac{1}{\rho}} \frac{1+I^{\gamma}}{1+\frac{1}{1+\delta} J^{\gamma}}>1, I_{\text {seg }}=I$ is an equilibrium and the segregated minority individuals have no incentives to deviate (integrate). Obviously, there exists $\hat{\rho}>0$ such that $\left(\frac{\left(1+J^{\gamma}\right) J}{\left(1+I^{\gamma}\right) I}\right)^{\frac{1}{\rho}} \frac{1+I^{\gamma}}{1+\frac{1}{1+\delta} J^{\gamma}}=1$. And because the left hand side is decreasing in $\rho$, which is easy to see, for any $\rho<\hat{\rho}$ it must be that $\omega\left(I_{\text {seg }}\right)_{I_{\text {seg }}=I}>1$. (A knife-edge possibility of a stable corner equilibrium is also that at the same time $\omega\left(I_{\text {seg }}\right)_{I_{\text {seg }}=I}=1$ and $\partial\left(W_{\text {seg }} / W_{\text {int }}\right) /\left.\partial I_{\text {seg }}\right|_{I_{\text {seg }}=I}<0$.) As concerns full integration, noting that $\operatorname{Lim}_{I_{\text {seg }} \rightarrow 0}(\omega)=\infty$, there are infinite returns to switching to segregated social network whenever $I_{\text {seg }}=0$. Therefore, $I_{\text {seg }}=0$ is never equilibrium in the model.

\section{Proof of Proposition 3}

Denote

$$
\begin{aligned}
& A(\chi) \equiv \frac{1+\left(I_{\text {seg }} \chi\right)^{\gamma}}{1+\left(\left(I-I_{\text {seg }}\right) \chi\right)^{\gamma}+\frac{1}{1+\delta}(J \chi)^{\gamma}} \\
& B(\chi) \equiv \frac{\left(1+\left(\left(I-I_{\text {seg }}\right) \chi\right)^{\gamma}+\frac{1}{1+\delta}(J \chi)^{\gamma}\right)\left(I-I_{\text {seg }}\right)+\left(1+\frac{1}{1+\delta}\left(\left(I-I_{\text {seg }}\right) \chi\right)^{\gamma}+(J \chi)^{\gamma}\right) J}{\left(1+\left(I_{\text {seg }} \chi\right)^{\gamma}\right) I_{\text {seg }}}
\end{aligned}
$$

and rewrite the arbitrage condition (AC') as a function of $\chi$ at a given $I_{\text {seg }}$ :

$$
\omega(\chi)=(B(\chi))^{\frac{1}{\rho}} A(\chi)=1
$$

Then differentiate $\omega(\chi)$ (holding $I_{\text {seg }}$ constant):

$$
\frac{\partial \omega(\chi)}{\partial \chi}=\frac{1}{\rho}(B(\chi))^{\frac{1-\rho}{\rho}} \frac{\partial B(\chi)}{\partial \chi} A(\chi)+(B(\chi))^{\frac{1}{\rho}} \frac{\partial A(\chi)}{\partial \chi}
$$


which implies that $\partial \omega(\chi) / \partial \chi<0$ is equivalent to:

$\frac{-1}{A(\chi)} \frac{\partial A(\chi)}{\partial \chi}>\frac{1}{\rho} \frac{1}{B(\chi)} \frac{\partial B(\chi)}{\partial \chi}$

Differentiating $A(\chi)$ with respect to $\chi$ one can show that $\frac{\partial A(\chi)}{\partial \chi}<0$ for any $I_{\text {seg }}$ that satisfies condition (IEC), thus in any interior equilibrium in particular. On the other hand, it can be similarly shown that $\frac{\partial B(\chi)}{\partial \chi}>0$ for any $I_{\text {seg }}$. Obviously, $\frac{\partial A(\chi)}{\partial \chi}$ and $\frac{\partial B(\chi)}{\partial \chi}$ are finite for any positive $\chi$. Moreover, $A(\chi)$ and $B(\chi)$ are both finite and positive. It follows that $\partial \omega(\chi) / \partial \chi<0$ whenever $\rho>\tilde{\rho} \equiv \frac{A(\chi)}{B(\chi)}\left(\frac{\partial B(\chi) / \partial \chi}{-\partial A(\chi) / \partial \chi}\right)$, where $\tilde{\rho}$ is well defined. It is also easy to see that if condition (IEC) is not satisfied, $\frac{\partial A(\chi)}{\partial \chi}>0$, therefore inequality (A.1) cannot be satisfied, and thus $\partial \omega(\chi) / \partial \chi>0$.

\section{Proof of Proposition 4}

Recalling the proof of Proposition 3, $\left.A(\chi)\right|_{I_{\text {seg }}=I} \equiv \frac{1+(I \chi)^{\gamma}}{1+\frac{1}{1+\delta}(J \chi)^{\gamma}} \quad$ and $\left.B(\chi)\right|_{I_{\text {seg }}=I} \equiv \frac{\left(1+(J \chi)^{\gamma}\right) J}{\left(1+(I \chi)^{\gamma}\right) I}$. Now realize that $\omega(\chi)_{\chi=0, I_{\text {seg }}=I}=(J / I)^{\frac{1}{\rho}}$, which is obviously larger than one for any $\rho$. Moreover, $\omega(\chi)_{\chi=0}=\left(\frac{\left(I-I_{\text {seg }}\right)+J}{I_{\text {seg }}}\right)^{\frac{1}{\rho}}$, which is clearly decreasing in $I_{\text {seg }}$. Therefore, if $\chi=0$, the only equilibrium is that of full segregation. Now realize that condition (IEC) for $I_{\text {seg }}=I$ boils down to $(1+\delta) I^{\gamma}<J^{\gamma}$. For $\chi=1$, $\omega(\chi)_{\chi=1, I_{\text {seg }}=I}=\left(\frac{\left(1+J^{\gamma}\right) J}{\left(1+I^{\gamma}\right) I}\right)^{\frac{1}{\rho}} \frac{1+I^{\gamma}}{1+\frac{1}{1+\delta} J^{\gamma}}$, which is less than one whenever $\rho>\rho_{1} \equiv \log \left(\frac{\left(1+J^{\gamma}\right) J}{\left(1+I^{\gamma}\right) I}\right) / \log \left(\frac{1+J^{\gamma} /(1+\delta)}{1+I^{\gamma}}\right) \quad$ and $\quad$ (IEC) holds. Moreover, differentiating $\omega(\chi)_{I_{\text {seg }}=I}=\left(\frac{\left(1+(J \chi)^{\gamma}\right) J}{\left(1+(I \chi)^{\gamma}\right) I}\right)^{\frac{1}{\rho}} \frac{1+(I \chi)^{\gamma}}{1+\frac{1}{1+\delta}(J \chi)^{\gamma}}$, one can show that $\left.\frac{\partial \omega(\chi)}{\partial \chi}\right|_{I_{\text {seg }=I}}<0$ for any $\chi$ whenever 
$\rho>\rho_{2} \equiv\left(\left((\chi J)^{\gamma}-(\chi I)^{\gamma}\right)\left(1+\frac{1}{1+\delta}(\chi J)^{\gamma}\right)\right) /\left(\left(1+\left(\chi^{J}\right)^{\gamma}\right)\left(\frac{1}{1+\delta}\left(\chi^{J}\right)^{\gamma}-(\chi I)^{\gamma}\right)\right) . \quad$ Now realize that both $\rho_{1}$ and $\rho_{2}$ are positive and well defined. Noting that $\omega(\chi)_{I_{\text {seg }}=I}=\left(\frac{\left(1+(J \chi)^{\gamma}\right) J}{\left(1+(I \chi)^{\gamma}\right) I}\right)^{\frac{1}{\rho}} \frac{1+(I \chi)^{\gamma}}{1+\frac{1}{1+\delta}(J \chi)^{\gamma}}$ is continuous in $\chi$, for $\rho>\hat{\rho} \equiv \operatorname{Max}\left|\rho_{1}, \rho_{2}\right|$ there must exist some $\hat{\chi} \in(0,1)$ such that $\omega(\hat{\chi})_{I_{\text {seg }}=I}=1$ and

(i) For any $\chi<\hat{\chi}$ full segregation is a stable equilibrium,

(ii) For any $\chi>\hat{\chi}$ full segregation is not a stable equilibrium and, because $\operatorname{Lim}_{I_{\text {seg }} \rightarrow 0}\left(\omega\left(I_{\text {seg }}\right)\right)=\infty$ and $\omega\left(I_{\text {seg }}\right)$ is continuous in $I_{\text {seg }}$, there exists a stable interior segregation equilibrium, $I_{\text {seg }}^{e} \in(0,1)$.

\section{Proof of Propositions 5a-b}

Recalling that $\Omega_{j} \equiv W_{i n t} H_{j}$ and $\Omega_{i, n t} \equiv W_{i n t} H_{i, i n t}, \frac{\partial \Omega_{j}}{\partial \chi}=\frac{\partial W_{i n t}}{\partial \chi} H_{j}+\frac{\partial H_{j}}{\partial \chi} W_{i n t}$ and $\frac{\partial \Omega_{i, i n t}}{\partial \chi}=\frac{\partial W_{i n t}}{\partial \chi} H_{i, \text { int }}+\frac{\partial H_{i, \text { int }}}{\partial \chi} W_{i n t}$. Knowing that $H_{j}>H_{i, \text { int }}, \frac{\partial W_{i n t}}{\partial \chi} H_{j}>\frac{\partial W_{i n t}}{\partial \chi} H_{i, \text { int }}$. So to establish that $\frac{\partial \Omega_{j}}{\partial \chi}>\frac{\partial \Omega_{i, \text { int }}}{\partial \chi}$ it suffices to show that $\frac{\partial H_{j}}{\partial \chi}>\frac{\partial H_{i, \text { int }}}{\partial \chi}$. Noting that $H_{i, n t}=1+\left(I_{\text {int }} \chi\right)^{\gamma}+\frac{1}{1+\delta}(J \chi)^{\gamma} \quad$ and $\quad H_{j}=1+\frac{1}{1+\delta}\left(I_{\text {int }} \chi\right)^{\gamma}+(J \chi)^{\gamma}$, $\frac{\partial H_{i, \text { int }}}{\partial \chi}=\gamma\left(I_{\text {int }} \chi\right)^{\gamma-1} I_{\text {int }}+\frac{1}{1+\delta} \gamma(J \chi)^{\gamma-1} J \quad$ and $\quad \frac{\partial H_{j}}{\partial \chi}=\frac{1}{1+\delta} \gamma\left(I_{\text {int }} \chi\right)^{\gamma-1} I_{\text {int }}+\gamma(J \chi)^{\gamma-1} J$. After some straightforward algebraic manipulation one can show that because $J>I_{\text {int }}$ and $\delta>0$ it must be that $\partial H_{j} / \partial \chi>\partial H_{i, \text { int }} / \partial \chi$ and thus $\partial \Omega_{j} / \partial \chi>\partial \Omega_{i, \text { int }} / \partial \chi$. To compare $\frac{\partial \Omega_{j}}{\partial \chi}$ and $\frac{\partial \Omega_{i, \text { seg }}}{\partial \chi}$, noting that segregated minority and majority do not receive the same wage, it is necessary to proceed as in the proof of Proposition 3 where the only change is that $A(\chi)$ is redefined: $A^{\prime}(\chi) \equiv \frac{1+\left(I_{\text {seg }} \chi\right)^{\gamma}}{1+\frac{1}{1+\delta}\left(\left(I-I_{\text {seg }}\right) \chi\right)^{\gamma}+(J \chi)^{\gamma}}$. All the rest of the proof of Proposition 3 applies here, the only exception being that it always holds that $\frac{\partial A(\chi)}{\partial \chi}<0$ and thus condition (IEC) is not necessary. This implies that $\partial \Omega_{j} / \partial \chi>\partial \Omega_{i, \text { int }} / \partial \chi$ whenever $\rho$ is large enough such as in the proof of Proposition 3 with $A^{\prime}(\chi)$ instead of $A(\chi)$ and the respectively redefined $\tilde{\rho}$. 


\section{Proof of Proposition 6}

Differentiating equations (3b) and (3c) with respect to $\chi$ and realizing that $I_{\text {seg }}^{e}$ is also a function of $\chi$ in the long run, one obtains:

$$
\begin{aligned}
& \frac{\partial H_{i, i n t}}{\partial \chi}=\frac{\gamma(J \chi)^{\gamma-1} J}{1+\delta}+\gamma\left(I_{i n t} \chi\right)^{\gamma-1}\left(I_{\text {int }}+\frac{\partial I_{\text {int }}}{\partial \chi} \chi\right) \\
& \frac{\partial H_{j}}{\partial \chi}=\gamma(J \chi)^{\gamma-1} J+\frac{\gamma\left(I_{\text {int }} \chi\right)^{\gamma-1}}{1+\delta}\left(I_{\text {int }}+\frac{\partial I_{\text {int }}}{\partial \chi} \chi\right) .
\end{aligned}
$$

From these results one obtains that $\partial H_{j} / \partial \chi>\partial H_{i, \text { int }} / \partial \chi$ is equivalent to the condition $\frac{\partial I_{\text {int }} / I_{\text {int }}}{\partial \chi / \chi}<\left(\frac{J}{I_{\text {int }}}\right)^{\gamma}-1$, for any positive $I_{\text {int }}$. If $I_{\text {int }}=0$, one can easily see from the derivatives above that $\partial H_{j} / \partial \chi>\partial H_{i, \text { int }} / \partial \chi$, because $\delta>0$. Clearly, only desegregation $\left(\partial I_{\text {int }}>0\right)$ can violate this condition, given that $\partial \chi>0$. Because $\partial \omega(\chi) / \partial \chi$ and $\partial \omega\left(I_{\text {seg }}\right) / \partial I_{\text {seg }}$ are non-zero and finite for any $I_{\text {seg }}>0$ and $\chi>0$, which is obvious from inspection of $\omega(\chi)$ above, $\partial I_{\text {seg }} / \partial \chi=-\frac{\partial \omega\left(I_{\text {seg }}, \chi\right) / \partial \chi}{\partial \omega\left(I_{\text {seg }}, \chi\right) / \partial I_{\text {seg }}}=-\partial I_{\text {int }} / \partial \chi$ is finite as well. But then there for any $I_{\text {int }} \in(0, I)$ and $0<\chi \leq 1$ there exists $\bar{y}>0$ such that for any $J / I>\bar{y}$ the condition $\frac{\partial I_{\text {int }} / I_{\text {int }}}{\partial \chi / \chi}<\left(\frac{J}{I_{\text {int }}}\right)^{\gamma}-1$ is satisfied. As in the previous proof, $\partial H_{j} / \partial \chi>\partial H_{i, \text { int }} / \partial \chi$ implies $\partial \Omega_{j} / \partial \chi>\partial \Omega_{i, \text { int }} / \partial \chi$. Because the arbitrage condition (AC) holds in the long run and thus $\Omega_{i, \text { int }}=\Omega_{i, \text { seg }}, \quad \partial \Omega_{j} / \partial \chi>\partial \Omega_{i, \text { int }} / \partial \chi$ implies that $\partial \Omega_{j} / \partial \chi>\partial \Omega_{i, \text { seg }} / \partial \chi$. 